\title{
PRO-FIBROTIC PHENOTYPE OF BONE MARROW STROMAL CELLS IN MODIC TYPE 1 CHANGES
}

\author{
I. Heggli ${ }^{1,2, *}$, S. Epprecht ${ }^{1,2}$, A. Juengel ${ }^{1,2}$, R. Schuepbach ${ }^{3}$, N. Farshad-Amacker ${ }^{4}$, C. German ${ }^{4}$, T. Mengis ${ }^{1,2}$, \\ N. Herger ${ }^{1,2}$, L. Straumann ${ }^{1,2}$, S. Baumgartner ${ }^{1,2}$, M. Betz ${ }^{5}$, J.M. Spirig ${ }^{5}$, F. Wanivenhaus ${ }^{5}$, N. Ulrich ${ }^{5}$, \\ D. Bellut ${ }^{6}$, F. Brunner ${ }^{2}$, M. Farshad ${ }^{5}$, O. Distler ${ }^{1,2}$ and S. Dudli ${ }^{1,2}$
}

${ }^{1}$ Center of Experimental Rheumatology, Department of Rheumatology, University Hospital, University of Zurich, Zurich, Switzerland

${ }^{2}$ Department of Physical Medicine and Rheumatology, Balgrist University Hospital, University of Zurich, Zurich, Switzerland

${ }^{3}$ Unit of Clinical and Applied Research, Balgrist University Hospital, University of Zurich, Zurich, Switzerland

${ }^{4}$ Department of Radiology, Balgrist University Hospital, University of Zurich, Zurich, Switzerland

${ }^{5}$ Department of Orthopaedic Surgery, Balgrist University Hospital, University of Zurich, Zurich, Switzerland

${ }^{6}$ Department of Neurosurgery, University Hospital Zurich, Zurich, Switzerland

\begin{abstract}
Modic type 1 changes (MC1) are painful vertebral bone marrow lesions frequently found in patients suffering from chronic low-back pain. Marrow fibrosis is a hallmark of MC1. Bone marrow stromal cells (BMSCs) are key players in other fibrotic bone marrow pathologies, yet their role in MC1 is unknown. The present study aimed to characterise MC1 BMSCs and hypothesised a pro-fibrotic role of BMSCs in MC1.

BMSCs were isolated from patients undergoing lumbar spinal fusion from $\mathrm{MC} 1$ and adjacent control vertebrae. Frequency of colony-forming unit fibroblast (CFU-F), expression of stem cell surface markers, differentiation capacity, transcriptome, matrix adhesion, cell contractility as well as expression of pro-collagen type I alpha 1, $\alpha$-smooth muscle actin, integrins and focal adhesion kinase (FAK) were compared.

More CFU-F and increased expression of C-X-C-motif-chemokine 12 were found in MC1 BMSCs, possibly indicating overrepresentation of a perisinusoidal BMSC population.

RNA sequencing analysis showed enrichment in extracellular matrix proteins and fibrosis-related signalling genes. Increases in pro-collagen type I alpha 1 expression, cell adhesion, cell contractility and phosphorylation of FAK provided further evidence for their pro-fibrotic phenotype. Moreover, a leptin receptor high expressing (LEPR ${ }^{\text {high }}$ ) BMSC population was identified that differentiated under transforming growth factor beta 1 stimulation into myofibroblasts in MC1 but not in control BMSCs.

In conclusion, pro-fibrotic changes in MC1 BMSCs and a LEPR ${ }^{\text {high }}$ MC1 BMSC subpopulation susceptible to myofibroblast differentiation were found. Fibrosis is a hallmark of $\mathrm{MC} 1$ and a potential therapeutic target. A causal link between the pro-fibrotic phenotype and clinical characteristics needs to be demonstrated.
\end{abstract}

Keywords: Modic change, fibrosis, bone marrow stromal cells, mesenchymal stem cell, extracellular matrix, cell differentiation, cell contractility, cell adhesion, focal adhesion kinase, pro-fibrotic phenotype.

*Address for correspondence: Irina Heggli, Centre of Experimental Rheumatology, Balgrist Campus AG, Lengghalde 5, 8008 Zurich, Switzerland.

Telephone number: +41 445107513 Email: irina.heggli@usz.ch

Copyright policy: This article is distributed in accordance with Creative Commons Attribution Licence (http://creativecommons.org/licenses/by-sa/4.0/).

\section{List of Abbreviations}

ACTA2

$\mathrm{bFGF}$

BMI actin alpha 2, smooth muscle

basic fibroblast growth factor

body mass index
BMSCs

BSA

CD

CFU-F

COL1A1 bone marrow stromal cells

bovine serum albumin cluster of differentiation colony-forming unit fibroblast collagen type I alpha 1 


\begin{tabular}{|c|c|}
\hline COL4A5 & collagen type IV alpha 5 \\
\hline CXCL12 & C-X-C-motif-chemokine 12 \\
\hline DEG & differentially expressed gene \\
\hline ECM & extracellular matrix \\
\hline EDTA & ethylenediaminetetraacetic acid \\
\hline ELISA & $\begin{array}{l}\text { enzyme-linked immunosorbent } \\
\text { assay }\end{array}$ \\
\hline EMT & $\begin{array}{l}\text { epithelial-myofibroblast } \\
\text { transformation }\end{array}$ \\
\hline FACS & fluorescence-activated cell sorting \\
\hline FAK & focal adhesion kinase \\
\hline FCS & foetal calf serum \\
\hline FN1 & fibronectin \\
\hline GAG & glycosaminoglycan \\
\hline GO & gene ontology \\
\hline GSEA & gene set enrichment analysis \\
\hline HEPES & $\begin{array}{l}\text { 2-[4-(2-hydroxyethyl)piperazin-1-yl] } \\
\text { ethanesulfonic acid }\end{array}$ \\
\hline HLA & human leukocyte antigen \\
\hline HPRT1 & $\begin{array}{l}\text { hypoxanthine } \\
\text { phosphoribosyltransferase } 1\end{array}$ \\
\hline HRP & horseradish peroxidase \\
\hline ID & study patient identification number \\
\hline IQR & inter quartile range \\
\hline LEPR & leptin receptor \\
\hline LEPR high & leptin receptor high \\
\hline LBP & low-back pain \\
\hline MC & Modic changes \\
\hline MC1 & Modic type 1 changes \\
\hline MFI & median fluorescence intensity \\
\hline micro-CT & micro-computed tomography \\
\hline MMP9 & matrix metallopeptidase 9 \\
\hline MRI & magnetic resonance imaging \\
\hline MSCs & mesenchymal stem cells \\
\hline NG2 & neural/glial antigen 2 \\
\hline NES & normalised enrichment score \\
\hline ODI & Oswestry disability index \\
\hline PBS & phosphate-buffered saline \\
\hline p-FAK & phosphorylated FAK \\
\hline PMT & pericyte-myofibroblast transition \\
\hline $\mathrm{P} / \mathrm{S}$ & penicillin/streptomycin \\
\hline PVDF & polyvinylidene difluoride \\
\hline qPCR & $\begin{array}{l}\text { quantitative polymerase chain } \\
\text { reaction }\end{array}$ \\
\hline RT-qPCR & real time qPCR \\
\hline $\mathrm{SD}^{1}$ & standard deviation \\
\hline SDS-PAGE & $\begin{array}{l}\text { sodium dodecyl sulphate- } \\
\text { polyacrylamide gel electrophoresis }\end{array}$ \\
\hline STIR & short tau inversion recovery \\
\hline TBS & tris-buffered saline \\
\hline TGF- $\beta 1$ & transforming growth factor beta 1 \\
\hline T1w & T1-weighted \\
\hline $\mathrm{T} 2 \mathrm{w}$ & T2-weighted \\
\hline VAS & visual analogue score \\
\hline VASback & visual analogue score for back pain \\
\hline VASleg & visual analogue score for leg pain \\
\hline$\alpha \mathrm{MEM}$ & $\begin{array}{l}\text { minimum essential medium alpha } \\
\text { modification }\end{array}$ \\
\hline$\alpha-S M A$ & alpha smooth muscle actin \\
\hline
\end{tabular}

\section{Introduction}

MC are vertebral bone marrow lesions visualised by MRI that occur around a degenerated intervertebral disc (Modic et al., 1988). Of the three interconvertible types of MC, MC1 has the highest association with LBP (Kääpä et al., 2012; Nguyen et al., 2015). LBP patients with MC1 report a higher frequency and duration of LBP episodes, seek care more often and have a higher risk for no improvement in pain and function (Chung et al., 2004; Jensen et al., 2008; Jensen et al., 2014; Schistad et al., 2014; Sørile et al., 2012). Larger lesions are more painful and have a positive predictive value for discography concordant pain of up to 100 \% (Järvinen et al., 2015; Weishaupt et al., 2001). In contrast to disc herniation, where nerve compression causes back and leg pain, MC pain originates from the endplate and vertebra (Fields et al., 2014; Lotz et al., 2013; Ohtori et al., 2006).

Despite the high clinical and socioeconomic importance, MC1 pathophysiology is largely unknown. Only a few studies have investigated human surgical MC1 bone marrow tissue. In Michael Modic's original paper, he described MC1 bone marrow based on three biopsies as a fibrovascular granulation tissue (Modic et al., 1988). Perilli et al. (2015) investigated nine MC1 biopsies by histology and micro-CT and concluded that MC1 had a high bone turnover possibly due to inflammation. In a cross-sectional analysis of MC1 bone marrow aspirates and of adjacent discs, Dudli et al. (2017) found pro-fibrotic changes (i.e. increased COL1A1 expression) in MC1 and a pro-fibrotic and proinflammatory cross-talk between MC1 bone marrow and the adjacent disc. In summary, these studies have identified fibrosis, inflammation and high bone turnover as the pathophysiological hallmarks of MC1. However, the fibrotic mechanism in MC1 remains largely unknown.

BMSCs are key regulators of bone marrow inflammation, fibrosis and bone turnover (Kondo et al., 2001; Schneider et al., 2017; Ziegler et al., 2016). BMSCs fulfil the criteria for MSCs (Dominici et al., 2006): they express CD73, CD90, CD105 but not CD14, CD19, CD34, CD45 and HLA-DR; they form CFU-F on plastic dishes and can differentiate into adipocytes, osteoblasts and chondrocytes. Primary BMSCs are a heterogeneous population and their reported markers include LEPR, CD54, CD106, CD140a, CD146, CD271, CXCL12, nestin and NG2 (El Agha et al., 2017a; Decker et al., 2017). Expression of specific markers has been associated with their bone marrow niche localisation. BMSCs from the endosteal niche are CD146 ${ }^{-}$while BMSCs from the vascular niche express CD106, CD146, CD271, CXCL12 and NG2 (Barilani et al., 2018; Tormin et al., 2011). Within the vascular niche, periarteriolar and perisinusoidal BMSCs can be distinguished based on their expression profile. Nestin expression is higher in periarteriolar BMSCs, 
while LEPR and CD106 is higher in sinusoidal BMSCs (El Agha et al., 2017a; Jacobsen et al., 1996). Expression of specific markers has also been linked to pathological conditions. For example, perivascular, LEPR-expressing BMSCs have been identified as the cellular origin of collagen-producing myofibroblasts in bone marrow fibrosis (Decker et al., 2017). These cells are profoundly dysregulated as evidenced by myelofibrosis, osteosclerosis and neoangiogenesis. Perivascular BMSCs are pericyte-like cells and Notch signalling promotes their PMT. Notch signalling is an important pro-fibrotic pathway affecting BMSC proliferation and differentiation (Azizidoost et al., 2015; Dong et al., 2010; Wang et al., 2019).

Despite the important role of BMSCs in fibrosis, their role in $\mathrm{MC1}$ is unknown. To gauge the role of BMSCs in MC1, MC1 BMSCs were compared to intrapatient control BMSCs from chronic LBP patients undergoing spinal fusion. The aim of the study was to identify and characterise potential pro-fibrotic attributes of MC1 BMSCs.

\section{Material and Methods}

The study was conducted in accordance with the Declaration of Helsinki and approved by the local Ethics Commission (\#2017-00761; approved June 05, 2017). Chemicals were purchased from SigmaAldrich if not stated otherwise.

\section{Study subjects}

Informed consent was obtained from each subject. The study included 14 patients undergoing lumbar spondylodesis at the Balgrist University Hospital between April 2018 and July 2020. Inclusion criteria were (i) spinal fusion at level of MC1 with a large enough MC1 lesion that a pedicle screw came to lie into the MC1 lesion, (ii) a second pedicle screw in a vertebral bone marrow region without $\mathrm{MC}$ from the same patient (Fig. 1). Exclusion criteria were applied based on past medical history and were infectious diseases, malignancies, prior instrumented back surgery, rheumatic markers e.g. HLA, autoantibodies, juvenile scoliosis and leg pain greater than back pain on VAS. Patients were identified preoperatively based on T1w, T2w and STIR lumbar MRI. Subjects completed a 10-item ODI questionnaire and indicated intensity of back and leg pain on a $10 \mathrm{~cm}$ VAS (VASback and VASleg, respectively). Patient demographics are summarised in Table 1.

Magnetic resonance images were retrospectively analysed by a radiologist with $>12$ years of experience including $>5$ years in musculoskeletal radiology. The MRI sequences available were sagittal T1w and sagittal T2w images, sagittal STIR, coronal T2w images, intra-operative $X$-ray as well as post-operative T1w and T2w sagittal images. Mean difference from date of surgery to MRI acquisition was $41.9 \pm 29.8 \mathrm{~d}$. The location of the Jamshidi needle tip during aspiration (or pedicle screw tip if no intraoperative X-ray were available) was determined and MC type (no MC, MC1, MC2, MC3) and extent (<50\%, > 50\% of vertebral body height) at needle tip location was rated. Total endplate score (0-6) (Rajasekaran et al., 2008) and Pfirmann grade of adjacent disc (0-5) were compared using paired Wilcoxon tests.

\section{Bone marrow aspirates and BMSC culture}

Spondylodesis requires the insertion of pedicle screws into the vertebral bodies. Using the pedicle screw trajectories, bone marrow aspirates were taken before screw insertion using a Jamshidi needle. Two aspirates were taken from each patient: a MC1 and an intra-patient control aspirate (Fig. 1). Proper positioning of the Jamshidi needle was key. In preoperative discussions with the surgeons and with intra-procedural radiographic guidance, proper needle position was ensured. Surgeons were advised to aspirate $2.5-3.5 \mathrm{~mL}$ bone marrow immediately after reaching the target depth. Aspirates were taken with a $10 \mathrm{~mL}$ syringe and transferred within $2 \mathrm{~min}$ into K2EDTA tubes (BD Bioscience). Bone marrow aspirates were centrifuged at $700 \times g$ and $4{ }^{\circ} \mathrm{C}$ for $15 \mathrm{~min}$. Bone marrow fat and plasma were removed and red blood cells were lysed.

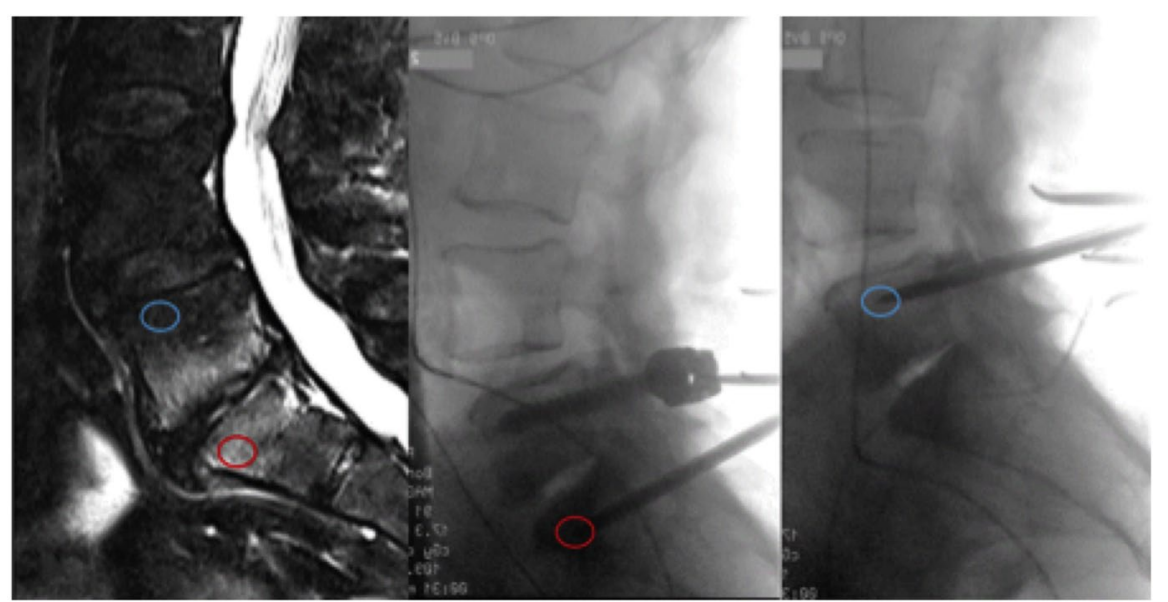

Fig. 1. MC1 at L5/S1. Pre-operative sagittal T2w MRI (left), intraoperative sagittal X-ray during harvesting of $\mathrm{MC1}$ aspirate (middle) and intra-patient control aspirate (right). Red and blue circle indicate location of MC1 and control aspirate, respectively. 


\begin{tabular}{|c|c|c|c|c|c|c|c|c|c|c|c|c|c|c|c|}
\hline 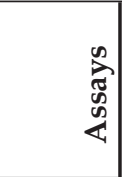 & 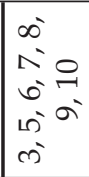 & 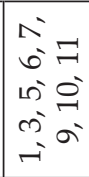 & 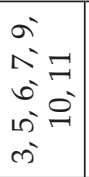 & 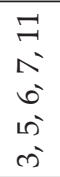 & 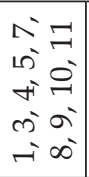 & 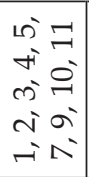 & 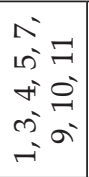 & 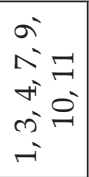 & 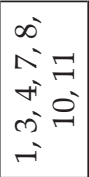 & 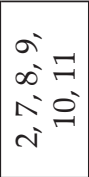 & $\begin{array}{l}0 \\
0 \\
a \\
\infty \\
\infty \\
i\end{array}$ & $\begin{array}{l}0 \\
\vdots \\
a \\
\infty \\
\infty \\
i\end{array}$ & $\begin{array}{l}\vec{z} \\
\text { i }\end{array}$ & $\overrightarrow{\text { v }}$ & \\
\hline 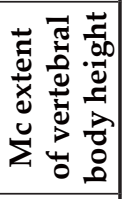 & $\begin{array}{l}\stackrel{0}{ } \\
\circ \\
10 \\
v\end{array}$ & $\begin{array}{l}0^{0} \\
0 \\
1 \\
\wedge\end{array}$ & $\begin{array}{l}\stackrel{0}{0} \\
\text { in } \\
v\end{array}$ & $\begin{array}{l}\stackrel{0}{ } \\
\circ \\
10 \\
v\end{array}$ & $\overleftrightarrow{Z}$ & $\begin{array}{l}\text { o̊ } \\
\text { டn } \\
\mathrm{v}\end{array}$ & $\begin{array}{l}\stackrel{0}{0} \\
\stackrel{\circ}{ } \\
v\end{array}$ & $\begin{array}{l}\circ \\
\circ \\
1 \\
1\end{array}$ & $\begin{array}{l}\circ \\
\circ \\
10 \\
1\end{array}$ & $\begin{array}{l}\stackrel{0}{0} \\
\stackrel{\circ}{10} \\
\wedge\end{array}$ & $\begin{array}{l}0^{0} \\
0 \\
10 \\
\wedge\end{array}$ & $\begin{array}{l}\stackrel{0}{ } \\
\circ \\
\stackrel{1}{0} \\
v\end{array}$ & $\begin{array}{l}0^{0} \\
0 \\
10 \\
\wedge\end{array}$ & $\begin{array}{l}\circ \\
0 \\
\circ \\
\wedge\end{array}$ & \\
\hline 品 & Ln & 0 & $r$ & 10 & 艺 & 0 & 0 & + & 10 & 0 & in & $\infty$ & Ln & in & $\begin{array}{r}\text { in } \\
\text { in } \\
10\end{array}$ \\
\hline 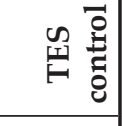 & H & 0 & - & $\infty$ & 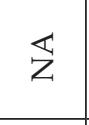 & $m$ & $r$ & 0 & $\infty$ & - & - & $\infty$ & + & - & $\infty \stackrel{\stackrel{\circ}{\rightleftarrows}}{=}$ \\
\hline 会 & Ln & 10 & 10 & Ln & 艺 & 10 & 10 & 10 & 10 & 10 & Ln & 10 & 10 & Ln & 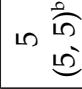 \\
\hline 合总 & in & in & 10 & in & ¿ & in & $\neg$ & 10 & Ln & $N$ & D & 10 & L & $\infty$ & 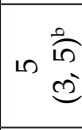 \\
\hline $\bar{U}$ & 10 & $\stackrel{10}{9}$ & $\bar{\omega}$ & $\stackrel{H}{\leftrightarrows}$ & $\stackrel{19}{9}$ & $\stackrel{1 \Omega}{a}$ & के & 3 & $\stackrel{\sharp}{\leftrightarrows}$ & $\stackrel{\sharp}{\leftrightarrows}$ & $\stackrel{103}{\hookrightarrow}$ & 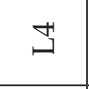 & $\stackrel{19}{\hookrightarrow}$ & $\bar{\omega}$ & \\
\hline 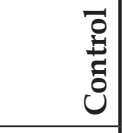 & 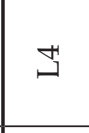 & $\mathcal{J}$ & 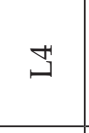 & 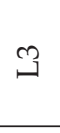 & 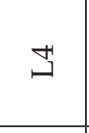 & $\bar{\omega}$ & $\stackrel{\Omega}{9}$ & $\stackrel{\Omega}{9}$ & 3 & $\mathcal{I}$ & $\stackrel{\sharp}{\leftrightarrows}$ & $\stackrel{2}{9}$ & 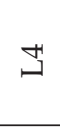 & $\stackrel{1}{a}$ & \\
\hline $\begin{array}{l}\hat{a} \\
\overline{0} \\
\overline{0}\end{array}$ & 8 & 8 & i & $\stackrel{\infty}{+}$ & $\overleftrightarrow{Z}$ & กี & กี & ిల & $\stackrel{\mathscr{N}}{\mathrm{N}}$ & 도 & $\infty$ & เి & $\stackrel{\infty}{\infty}$ & 过 & 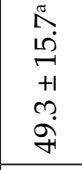 \\
\hline$\frac{800}{\frac{00}{n}}$ & $\sigma$ & 0 & 飞 & $\infty$ & ¿ & 0 & $\infty$ & 6 & 0 & $\wedge$ & $a$ & $\infty$ & L & $\infty$ & 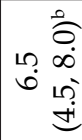 \\
\hline 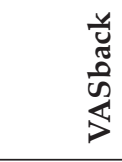 & $a$ & $\sigma$ & 乙 & $\sigma$ & 0 & $\infty$ & $\infty$ & 6 & $\infty$ & 0 & $\sigma$ & $\wedge$ & $\wedge$ & H & 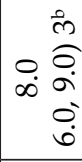 \\
\hline 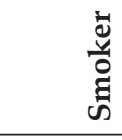 & $\stackrel{\mathscr{D}}{\beth}$ & \& & \& & ‡ & $\stackrel{\infty}{D}$ & ‡ & $\stackrel{\mathscr{D}}{2}$ & $\stackrel{\infty}{\triangleright}$ & \& & ‡ & ‡ & $\stackrel{\mathscr{Z}}{\mathscr{Z}}$ & 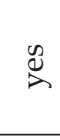 & \& & $\begin{array}{l}\stackrel{2}{\circ} \\
\text { ఫे }\end{array}$ \\
\hline 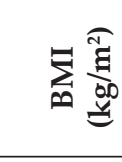 & 品 & $\stackrel{n}{\vec{\infty}}$ & $\begin{array}{l}\overrightarrow{0} \\
\infty \\
\infty\end{array}$ & $\begin{array}{l}0 \\
\dot{\theta}\end{array}$ & $\vec{c}$ & 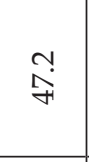 & $\begin{array}{l}H \\
\infty \\
\infty\end{array}$ & तु & $\stackrel{\text { Ln }}{\stackrel{\text { mे }}{n}}$ & @̊. & 户े & 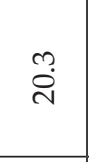 & : & $\stackrel{\widehat{D}}{\stackrel{N}{ }}$ & 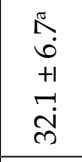 \\
\hline 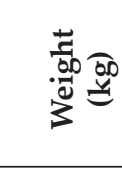 & $\sigma$ & $\begin{array}{l}0 \\
\stackrel{0}{0}\end{array}$ & ڤִ & $\stackrel{R}{\Lambda}$ & $\stackrel{\wedge}{\infty}$ & 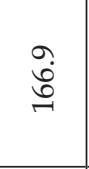 & ฉ & ְై & ఉ & 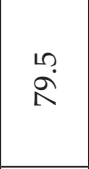 & 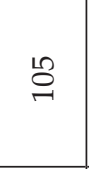 & 8 & 8 & $\begin{array}{l}\infty \\
\qquad 8 \\
\qquad 0\end{array}$ & 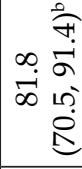 \\
\hline 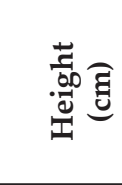 & $\underset{\sim}{\sigma}$ & Lొ & $\stackrel{\stackrel{\llcorner}{R}}{\sim}$ & 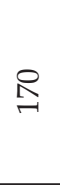 & $\stackrel{\vec{n}}{\sim}$ & $\stackrel{\infty}{\infty}$ & $\stackrel{\mathscr{\Omega}}{\sim}$ & $\underset{\infty}{\infty}$ & $\stackrel{\text { ڤొ }}{\sim}$ & $\underset{\sim}{\sigma}$ & $\stackrel{\text { H }}{\Delta}$ & $\stackrel{N}{N}$ & $\stackrel{3}{\sim}$ & $\stackrel{8}{\circ}$ & 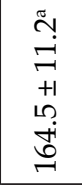 \\
\hline ஸे & $w$ & $\psi$ & $\psi$ & 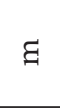 & $\omega$ & $\Xi$ & $\omega$ & 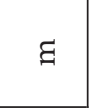 & 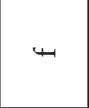 & 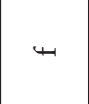 & $\omega$ & $\psi$ & $\psi$ & $\omega$ & 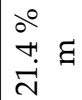 \\
\hline$\stackrel{\square}{40}$ & $尺$ & $\infty$ & 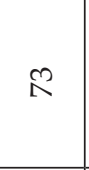 & $\infty$ & $\stackrel{\infty}{\infty}$ & $\infty$ & $\begin{array}{l}\infty \\
1\end{array}$ & 는 & $\stackrel{10}{\wedge}$ & $\cong$ & டे & $\stackrel{\llcorner}{\llcorner}$ & $\infty$ & 5 & 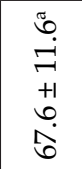 \\
\hline 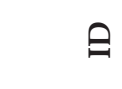 & $r$ & $N$ & $m$ & + & in & 0 & $\Lambda$ & $\infty$ & $\sigma$ & $\stackrel{?}{\sim}$ & $F$ & 그 & $\stackrel{2}{\longrightarrow}$ & $\nexists$ & $\begin{array}{c}\text { चू के } \\
\sum^{2}+1\end{array}$ \\
\hline
\end{tabular}


Table 2. BMSCs from MC1 and control bone marrow were characterised using 12 different assays.

\begin{tabular}{|c|c|c|c|}
\hline Assay & Test parameter & Method & $n$ \\
\hline 1 & Stem cell marker expression & Flow cytometry & 6 \\
\hline 2 & BMSC identity markers & Flow cytometry & 5 \\
\hline \multirow{2}{*}{3} & Differentiation capacity & \multirow{2}{*}{ Histology } & $8-9$ \\
\hline & Adipogenic differentiation LEPR ${ }^{\text {high }}$ & & 3 \\
\hline 4 & Incidence of BMSCs & CFU-F & 6 \\
\hline 5 & Gene expression & Bulk RNA sequencing & 4 \\
\hline 6 & Gene expression & RT-qPCR & $5-9$ \\
\hline 7 & Pro-collagen type I alpha 1 synthesis & ELISA & 6 \\
\hline 8 & Collagen contraction & In vitro functional assay & 7 \\
\hline 9 & $\alpha$-SMA, FAK/p-FAK synthesis & Western blot & $7-10$ \\
\hline 10 & Adhesion capacity & In vitro functional assay & $8-11$ \\
\hline \multirow{4}{*}{11} & TGF- $\beta 1$ stimulated gene expression & RT-qPCR & $5-7$ \\
\hline & TGF- $\beta 1$ stimulated $\alpha$-SMA synthesis & Western blot & 5 \\
\hline & TGF- $\beta 1$ stimulated collagen contraction & In vitro functional assay & 5 \\
\hline & TGF- $\beta 1$ stimulated $\alpha$-SMA synthesis (LEPR ${ }^{\text {high }}$ ) & Western blot & 3-4 \\
\hline 12 & Sorting of LEPR ${ }^{\text {high }}$ BMSCs & Fluorescence activated cell sorting & $3-4$ \\
\hline
\end{tabular}

BMSCs were isolated by plastic adherence (Dominici et al., 2006; Hoch and Leach, 2015). $30 \times 10^{6}$ cells were resuspended in growth medium [ $\alpha$ MEM without nucleosides $\left(\mathrm{Gibco}^{\mathrm{TM}}\right), 50 \mathrm{U} /$ $\mathrm{mL} \mathrm{P} / \mathrm{S}$ (Gibco), $10 \mathrm{mmol} / \mathrm{L}$ HEPES (Gibco), $10 \%$ heat-inactivated FCS and $2.5 \mathrm{ng} / \mathrm{mL}$ human bFGF (PeproTech)] and seeded in T75 flasks. Cells were incubated at $37^{\circ} \mathrm{C}$ and $5 \% \mathrm{CO}_{2}$ with medium change every 3-4 d. For all assays, BMSCs from passage 3-5 were used (Table 2). MC1 BMSCs and control BMSCs were used at the same passage for each patient. The performed assays for each patient are indicated in Table 1.

\section{Assay 1 and 2: flow cytometric characterisation}

In assay 1, stem cell surface markers CD105, CD73, CD90, CD45, CD34, CD14 and CD19 were stained for $45 \mathrm{~min}$ at room temperature (Table 3), washed with FACS buffer ( $\mathrm{PBS}$ without $\mathrm{Ca}^{2+}$ and $\mathrm{Mg}^{2+}, 1 \% \mathrm{FCS}$ ) and analysed using a BD LSRFortessa ${ }^{\mathrm{TM}}$ Flow Cytometer. Single measures of $\mathrm{MC} 1$ and control BMSCs were performed. Ratio of $\mathrm{CD}^{+} 3^{+}, \mathrm{CD}^{+} 0^{+}, \mathrm{CD} 105^{+}, \mathrm{CD} 45^{-}$, CD34-, CD14-, CD19- cells was calculated using FlowJo (version 10.7.1) and compared between MC1 and control BMSCs by paired $t$-test.

In assay 2, for intracellular epitopes (nestin, CXCL12) measurement, cells were permeabilised using BD FACS ${ }^{\mathrm{TM}}$ Permeabilizing Solution 2 according to manufacturer's protocol. Cells were stained either for CD54, CD106, CD140a, CD146, CD271, LEPR, NG2, CXCL12 or nestin for $45 \mathrm{~min}$ at room temperature (Table 3), washed with FACS buffer and analysed using BD LSRFortessa ${ }^{\mathrm{TM}}$ Flow Cytometer. Single measures of MC1 and control BMSCs were performed. The non-normal distributed difference of MC1 and control MFI was tested against null hypothesis $(\mu 0=0)$ by Wilcoxon test. Pearson correlation coefficients were calculated between different markers.

\section{Assay 3: differentiation capacity}

Adipogenesis was induced in sextuplicate in 80$90 \%$ confluent BMSC layers in 24-well plates with inductive medium ( $\alpha$ MEM no nucleosides medium, $50 \mathrm{U} / \mathrm{mL} \mathrm{P} / \mathrm{S}, 10 \mathrm{mmol} / \mathrm{L} \mathrm{HEPES}, 10 \% \mathrm{FCS}, 5 \mu \mathrm{g} /$ $\mathrm{mL}$ insulin, $10^{-7} \mathrm{~mol} / \mathrm{L}$ dexamethasone, $0.5 \mathrm{mmol} / \mathrm{L}$ isobutylmethylxanthine, $60 \mu \mathrm{mol} / \mathrm{L}$ indomethacin). Inductive medium was changed every $3 \mathrm{~d}$. BMSCs were fixed when MC1 and control cells showed fat droplets (after 14-21 d, same day for MC1 and control). Lipid droplets were stained with oil red $\mathrm{O}$ solution. After rinsing with $50 \%$ ethanol and distilled water, oil red $\mathrm{O}$ was dissolved in $100 \%$ 2-propanol and absorbance was read at $500 \mathrm{~nm}$. Median absorbances of sextuplicate were calculated. MC1 was normalised to control (100 \%) and tested against null hypothesis $(\mu 0=100 \%)$ using one sample $t$-test.

Osteogenesis was induced in sextuplicate of $100 \%$ confluent BMSC layers in 24-well plates with inductive medium ( $\alpha$ MEM no nucleosides medium, $50 \mathrm{U} / \mathrm{mL} \mathrm{P} / \mathrm{S}, 10 \mathrm{mmol} / \mathrm{L} \mathrm{HEPES}, 10 \% \mathrm{FCS}, 10^{-7} \mathrm{~mol} / \mathrm{L}$ dexamethasone, $10 \mathrm{mmol} / \mathrm{L} \beta$ glycerophosphate, $50 \mu \mathrm{mol} / \mathrm{L} \mathrm{L}$-ascorbic acid 2-phosphate). Inductive medium was changed every $3 \mathrm{~d}$. BMSCs were fixed after 21 to $28 \mathrm{~d}$ (same day for MC1 and control) and stained with a $2 \%$ alizarin red solution. The staining was dissolved with $10 \%$ cetylpyridiniumchloride solution and absorbance was read at $570 \mathrm{~nm}$. Median absorbances were calculated. MC1 was normalised to control $(100 \%)$ and tested against null hypothesis ( $\mu 0=100 \%)$ using one sample $t$-test.

Chondrogenesis was induced in BMSC pellets $\left(0.3 \times 10^{6}\right.$ cells $)$ seeded in sextuplicate on 96well ultra-low attachment U-bottom plates with 
Table 3. Conjugated antibodies used for flow cytometry. PE: phycoerythrin; FITC: fluorescein; PerCP: peridinin-chlorophyll-protein; BV: brilliant violet; APC: allophycocyanin; Cy7: cyanin 7.

\begin{tabular}{|c|c|c|}
\hline Antibody & Manufacturer & Dye \\
\hline CD105 & Biolegend & PE \\
\hline CD90 & Abcam & FITC \\
\hline CD73 & Biolegend & APC \\
\hline CD45 & Biolegend & PerCp \\
\hline CD34 & Biolegend & BV421 \\
\hline CD14 & Biolegend & APC/Cy7 \\
\hline CD19 & Biolegend & BV605 \\
\hline CD54 & Thermo Fisher Scientific & PE \\
\hline CD106 & Biolegend & PE \\
\hline CD140a & Thermo Fisher Scientific & PE \\
\hline CD146 & Thermo Fisher Scientific & PE \\
\hline CD271 & Biolegend & PE \\
\hline LEPR & Milteny Biotech & APC-Vio770 \\
\hline NG2 & Thermo Fisher Scientific & PE \\
\hline CXCL12 & R\&D Systems & PE \\
\hline Nestin & Biolegend & PE \\
\hline
\end{tabular}

inductive medium (DMEM high glucose, $50 \mathrm{U} / \mathrm{mL}$ $\mathrm{P} / \mathrm{S}, 10 \mathrm{mmol} / \mathrm{L}$ HEPES, $10^{-7} \mathrm{~mol} / \mathrm{L}$ dexamethasone, $1 \%$ insulin-transferrin-sodium selenite medium supplement, $1 \%$ non-essential amino acid, $0.05 \mathrm{mmol} / \mathrm{L}$ L-ascorbic acid-2-phosphate, $10 \mathrm{ng} / \mathrm{mL}$ recombinant human TGF- $\beta 1$ ). Medium was changed every $3 \mathrm{~d}$. Cells were fixed after $28 \mathrm{~d}$. 2 to 3 pellets were pooled and digested overnight with papain $\left(60{ }^{\circ} \mathrm{C}, 125 \mathrm{ug} / \mathrm{mL}\right.$ dissolved in $5 \mathrm{mmol} / \mathrm{L}$ L-cysteine $\mathrm{HCl}, 5 \mathrm{mmol} / \mathrm{L} \mathrm{Na}$-citrate, $150 \mathrm{mmol} / \mathrm{L} \mathrm{NaCl}$, $5 \mathrm{mmol} / \mathrm{L}$ EDTA, pH 6.0). DNA was quantified using DNA quantification Kit according to manufacturer's protocol. GAG was quantified using 1,9-dimethylmethylene blue assay (Enobakhare et al., 1996). Median GAG/DNA of control samples was set to $100 \%$. Relative GAG/DNA of MC1 samples was calculated and tested against null hypothesis ( $\mu 0=100 \%$ ) using one sample $t$-test.

\section{Assay 4: incidence of BMSCs (CFU-F)}

After red blood cell lysis of freshly harvested bone marrow aspirates, 5-10 × 106 nucleated bone marrow cells were seeded on a $60 \mathrm{~cm}^{2}$ Petri dish in growth medium and cultured for 10-15 d. Cells were fixed and colonies were stained with $0.1 \%$ crystal violet solution, imaged and manually counted (ImageJ v1.52p). Single measures of MC1 and control BMSCs were performed. Colony number from control bone marrow was set as $100 \%$. Relative MC1 colony count was calculated and tested against null hypothesis $(\mu 0=100 \%)$ using one sample $t$-test.

\section{Assay 5: bulk RNA sequencing}

RNA was isolated from BMSCs harvested at 90$100 \%$ confluency using miRNeasy Mini Kit (Qiagen) according to the manufacturer's protocol. The library was prepared with an input of $150 \mathrm{ng}$ total RNA using the TruSeq ${ }^{\circledR}$ Stranded total RNA preparation kit (Illumina). Ribosomal RNA was depleted using the Ribo-Zero Gold kit (Illumina). Libraries were sequenced using the HiSeq 4000 (Illumina) sequencer (paired-end sequencing, 151 cycles, > 40 million reads per sample). The quality of data readings was checked using Fast QC. Adaptor sequences at the 3' ends were removed and 4 bases at each end were trimmed with Trimmomatic (v0.36). Readings with $>30$ nt were analysed. Readings were mapped to the reference genome hg38 (STAR; 2.6.0c), counted using FeatureCounts and statistical analysis was performed using EdgeR (v3.22.1). Genes were considered to be differentially expressed for $p<0.01$ and $\log _{2}$ fold change $> \pm 0.5$. GO enrichment analysis was performed using Metacore (version 19.4) and DAVID (version 6.8) databases. GSEA was carried out with the GSEA software v4.1.0 (UC San Diego and Broad Institute, San Diego, CA, USA) (Subramanian et al., 2005) using signal to noise as gene ranking metric and 1,000 random permutations of the gene set. The analysis was performed with all hallmark gene sets from the Molecular Signatures Database (MSigDB) v7.1 (Subramanian et al., 2005) and for a specific fibrosis gene set (Wohlfahrt et al., 2019). Gene sets were considered to be enriched with FDR $q$-value $<0.1$. Enrichment map visualisation was carried out in the GSEA software v4.1.0 using GSEA result of c2.cp. reactome with $p<0.01$, FDR $q$-value $<0.1$ and network was visualised in Cytoscape version 3.8.0 using an overlap coefficient of 0.5 . RNA sequencing data is available at the European Nucleotide Archive (ENA) at EMBL-EBI under accession number PRJEB39993 (Web ref. 1).

\section{Assay 6: RT-qPCR}

RNA was isolated as described above. Reverse transcription and qPCR were done according to manufacturer's protocol (Labgene, Châtel-SaintDenis, Switzerland). Briefly, cDNA was synthesised using the SensiFAST cDNA Synthesis Kit using 100 ng RNA. Gene expression was quantified using Mic Real-Time PCR system (Labgene) and the SensiFAST ${ }^{\mathrm{TM}} \mathrm{SYBR}^{\circledR}$ No-ROX Kit (Table 4) adding $2.5 \%$ input of total cDNA. 40 cycles of $5 \mathrm{~s} 95{ }^{\circ} \mathrm{C}$, $20 \mathrm{~s} 60^{\circ} \mathrm{C}$, $10 \mathrm{~s} 72{ }^{\circ} \mathrm{C}$ were run followed by melting curve analysis. Samples were measured in technical duplicates and melting curves were analysed to ensure amplification of single products. For the COL4A5 (Hs01012435_m1), TaqMan probes were used with SensiFAST Probe No-ROX Kit. 50 cycles of $5 \mathrm{~s} 95^{\circ} \mathrm{C}, 40 \mathrm{~s} 60^{\circ} \mathrm{C}$ were run and single measures were performed. Gene expression was quantified using the $\triangle \triangle \mathrm{Cq}$ method with HPRT1 as a reference gene. $\Delta \Delta \mathrm{Cq}$ values were tested against the null hypothesis $(\mu 0=0)$ with one sample $t$-test.

\section{Assay 7: ELISA for pro-collagen type I alpha 1}

BMSCs were grown in duplicates to 90-100\% confluency in growth medium and cultured for $48 \mathrm{~h}$ 
Table 4. Primer pairs used for SYBR green RT-qPCR. ITGA: integrin subunit alpha; ITGB: integrin subunit beta.

\begin{tabular}{|c|c|c|}
\hline Target & Forward primer $\left(5^{\prime}-3^{\prime}\right)$ & Reverse primer $\left(5^{\prime}-3^{\prime}\right)$ \\
\hline HPRT1 & AGAATGTCTTGATTGTGGAAGA & ACCTTGACCATCTTTGGATTA \\
\hline ACTA2 & GACAATGGCTCTGGGCTCTGTAA & ATGCCATGTTCTATCGGGTACTT \\
\hline COL1A1 & CCGATGGATTCCAGTTCGAG & GGTAGGTGATGTTCTGGGAG \\
\hline MMP9 & GGATACAGTTTGTTCCTCGT & CTCAGTGAAGCGGTACATAG \\
\hline FN1 & TACACTGGGAACACTTACCG & CCAATCTTGTAGGACTGACC \\
\hline ITGA1 & GGTTCCTACTTTGGCAGTATT & AACCTTGTCTGATTGAGAGCA \\
\hline ITGA2 & GGAACGGGACTTTCGCAT & GGTACTTCGGCTTTCTCATCA \\
\hline ITGA3 & AAGGGACCTTCAGGTGCA & TGTAGCCGGTGATTTACCAT \\
\hline ITGA4 & GCTTCTCAGATCTGCTCGTG & GTCACTTCCAACGAGGTTTG \\
\hline ITGA5 & GTCGGGGGCTTCAACTTAGAC & CCTGGCTGGCTGGTATTAGC \\
\hline ITGA6 & GAGCTTTTGTGATGGGCGATT & СТСТССАССААСТTСАTAAGGC \\
\hline ITGA7 & CTGTTTCAGCTACATTGCAGTC & GCCTGGTGCTTGGGTTCT \\
\hline ITGA8 & AAAAGCAGACGGAAGTGGCT & AGCAGCAACTGAGTATCCAAGG \\
\hline ITGA9 & CAAAGGCATCGGCAAGGTTT & TCCCCATTCAGGTCAACTGC \\
\hline ITGA10 & TGTTCTTGCCCCTGGTGTTC & CCAGCATCCATCGCTGTCC \\
\hline ITGA11 & GGAGGAAGACTTGCGTCG & CACAGGTTCCCCAGTAGATG \\
\hline ITGAV & CTACCTCTGTGCCGCGCCTT & CCCACGAGAAGAAACATCCGGGAAG \\
\hline ITGB1 & GCCTTACATTAGCACAACACC & CATCTCCAGCAAAGTGAAAC \\
\hline ITGB2 & TTCGGGTCCTTCGTGGACA & ACTGGTTGGAGTTGTTGGTCA \\
\hline ITGB3 & TCCAGAGGAAGGGACACCAA & GCAGAGGTACAGATGACCCG \\
\hline ITGB5 & GGAGCCAGAGTGTGGAAACA & GAAACTTTGCAAACTCССТC \\
\hline ITGB7 & GCACGCACCTATGTGGAAAC & TCCCAAGCCGTAGTGGTAGA \\
\hline ITGB8 & AATTTGGTAGTGGAAGCCTATC & GTCACGTTTCTGCATCCTTC \\
\hline
\end{tabular}

in starvation medium with $1 \%$ FCS. After medium change, medium was conditioned for $24 \mathrm{~h}$. A 75-fold dilution was assayed for pro-collagen type I alpha 1 using Human Pro-Collagen I alpha 1 DuoSet (R\&D Systems) according to manufacturer's protocol. Samples were measured in technical duplicates. The non-normally distributed concentrations were compared between $\mathrm{MC} 1$ and control using paired Wilcoxon test.

\section{Assay 8: collagen contraction assay}

BMSCs $\left(0.2 \times 10^{6}\right.$ in $1.2 \mathrm{~mL}$ starvation medium $)$ were mixed with $600 \mu \mathrm{L}$ of $3 \mathrm{mg} / \mathrm{mL}$ rat tail collagen I (Corning), $0.1 \%$ acetic acid and $10 \mathrm{mmol} / \mathrm{L} \mathrm{NaOH}$. $500 \mu \mathrm{L}$ of this mixture was added to a 24 well ultralow attachment plate, covered with $500 \mu \mathrm{L}$ starvation medium and incubated at $37^{\circ} \mathrm{C}$ and $5 \% \mathrm{CO}_{2}$. Samples were measured in biological triplicates. Gels were imaged after $24 \mathrm{~h}$ and surface area was measured using Image J (version 1.52p). Size of MC1 BMSC gels was normalised to control BMSC gels (100\%) of the same patient tested against null hypothesis ( $\mu 0=100 \%)$ using one sample $t$-test.

\section{Assay 9: Western blot}

Confluent layers of BMSCs were lysed in Laemmli buffer. Proteins were separated with SDS-PAGE on $10 \%$ polyacrylamide gels and transferred to PVDF membranes using the Trans-Blot ${ }^{\circledR}$ Turbo ${ }^{\text {TM }}$ Transfer System (BioRad). Membranes were blocked for $3 \mathrm{~h}$ with $5 \%(\mathrm{w} / \mathrm{v})$ non-fat dry milk (or $3 \%$ BSA in case of p-FAK) in TBS with $0.1 \%(\mathrm{v} / \mathrm{v})$ Tween $^{\circledR} 20$ and incubated overnight in $3 \%(\mathrm{w} / \mathrm{v})$ BSA in TBS with $0.1 \%(\mathrm{v} / \mathrm{v})$ Tween ${ }^{\circledR} 20$ and with primary antibodies from Cell Signaling Technologies: 1 : 1,000 rabbit anti-human $\beta$-actin (\#8457), 1 : 1,000 rabbit antihuman FAK (\#3285), $1: 1,000$ rabbit anti-human p-FAK (Tyr397) (\#3283), 1 : 1,000 rabbit anti-human integrin $\beta 1$ (\#4706); or from Lucerna: $1: 2,000$ rabbit anti-human $\alpha$-SMA (GTX100034). Membranes were incubated with HRP-conjugated goat anti-rabbit immunoglobulin G (IgG) (7074, Cell Signaling Technologies, $1: 3,000$ ) and chemiluminescence was detected using the UltraScence Pico Ultra Western Substrate (Bio-Helix, Keelung City, Taiwan) on a BioRad VersaDoc. Single measures of MC1 and control BMSCs were performed. Signal intensities 
of bands were determined using Image $\mathrm{J}$ (version 1.52a). Band intensities of $\alpha$-SMA and FAK were normalised to $\beta$-actin and $p$-FAK was normalised to FAK. Percentages of MC1 and control intensities were compared by paired Wilcoxon test.

\section{Assay 10: adhesion assay}

BMSC adhesion to fibronectin-coated, collagen I-coated and uncoated surface was assessed. 96-well plates were coated overnight at $4{ }^{\circ} \mathrm{C}$ using $16 \mu \mathrm{g} /$ $\mathrm{mL}$ fibronectin or $0.75 \mathrm{mg} / \mathrm{mL}$ collagen I (Corning). Fibronectin- and collagen I-coated wells were blocked for non-specific binding with $1 \%$ heat-inactivated BSA for $1 \mathrm{~h}$ at $37^{\circ} \mathrm{C}$. 2,500 cells/well were seeded in sextuplets. After $15 \mathrm{~min}, 30 \mathrm{~min}$ and $4 \mathrm{~h}$, cell suspension was removed and non-adherent cells were washed away with PBS. Adherent cells were fixed using $4 \%$ neutral buffered formalin and stained with Hoechst 33342 (ThermoFisher Scientific). 4 images per well were taken at predefined spots using a Nikon Eclipse Ti2 upright brightfield microscope. Cells were counted manually using ImageJ. Cell counts at $15 \mathrm{~min}$ and $30 \mathrm{~min}$ were normalised to the respective $4 \mathrm{~h}$ count. Percentage increase of adherent MC1 and control BMSCs between 15 min (settling time) and 30 min were calculated and compared using a paired $t$-test.

\section{Assay 11: TGF- $\beta 1$ stimulation}

The capacity of $\mathrm{MC} 1$ and control BMSCs to differentiate into myofibroblast was tested using TGF- $\beta 1$ stimulation [ $24 \mathrm{~h}$ with $10 \mathrm{ng} / \mathrm{mL}$ recombinant human a

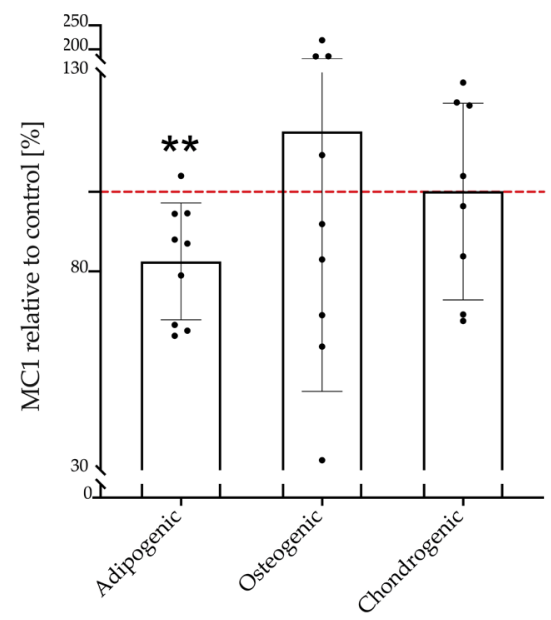

C

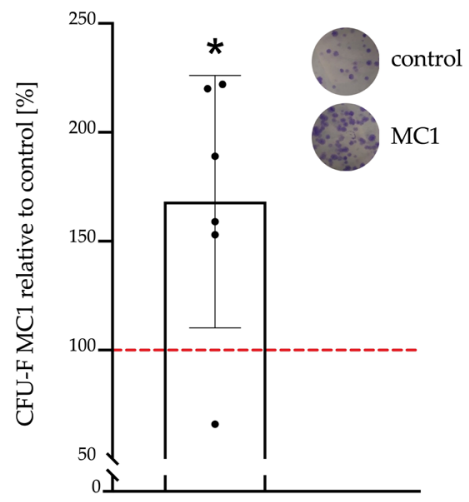

b

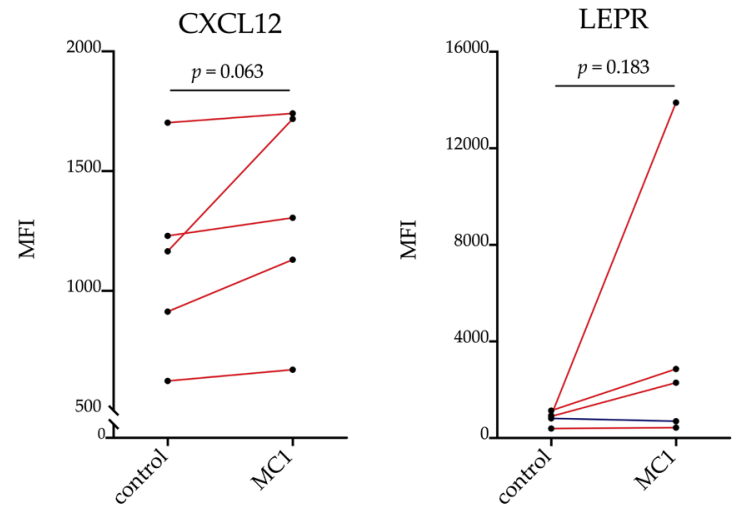

Fig. 2. Population and stemness characterisation of MC1 BMSCs. (a) MC1 BMSCs had a reduced adipogenic differentiation capacity. Adipogenic, osteogenic and chondrogenic differentiation capacity of MC1 and intra-patient control was measured in sextuplicate [adipogenesis, osteogenesis $(n=9+9)$, chondrogenesis $(n=8+8)]$. MC1 were normalised to intra-patient control $(100 \%)$ and tested against null hypothesis $(\mu 0=100 \%)$ using one sample $t$-test. (b) Trend towards increased expression of CXCL12 and LEPR in MC1. CXCL12 and LEPR expression was analysed by flow cytometry. Difference in MC1 to control $\triangle \mathrm{MFI}$ was tested against null hypothesis $(\mu 0=0)$ using Wilcoxon test. Single measures of $\mathrm{MC} 1$ and control were performed $(n=5+5)$. (c) Increased incidence of BMSCs in MC1. CFU-F from MC1 and control bone marrow mononuclear cells were fixed, stained and manually counted using Image J. Colony number from control bone marrow was set as $100 \%$. Relative MC1 colony count was calculated and tested against null hypothesis $(\mu 0=100 \%)$ using one sample $t$-test $(n=6+6)$. Single measures of MC1 and control were performed. ${ }^{*} p<0.05,{ }^{* *} p<0.01$. 
Table 5. Changes in the expression of BMSC surface markers. Differences (MC1-control) of MFI ( $\triangle \mathrm{MFI})$ with IQR in flow cytometric analysis are indicated.

\begin{tabular}{|c|c|c|c|c|}
\hline Protein code & Protein name & $\begin{array}{c}\Delta \text { MFI } \\
\text { (MC1-control) }\end{array}$ & IQR & $p$ \\
\hline LEPR & Leptin receptor & 1395 & 42,1724 & 0.188 \\
\hline CD146 & Melanoma cell adhesion molecule (MCAM) & -231 & $-403,482$ & 1.000 \\
\hline CD271 & Low-affinity nerve growth factor receptor & -157 & $-265,1811$ & 1.000 \\
\hline CXCL12 & Stromal cell-derived factor 1 (SDF-1) & 75 & 47,217 & 0.063 \\
\hline CD54 & Intercellular adhesion molecule 1 (ICAM-1) & 43 & $-508,158$ & 1.000 \\
\hline Nestin & Nestin & 1081 & 974,3329 & 0.625 \\
\hline NG2 & Neural/glial antigen 2 & -457 & $-1313,41$ & 0.625 \\
\hline CD140a & Platelet-derived growth factor receptor A & -810 & $-1116,88$ & 0.625 \\
\hline CD106 & Vascular cell adhesion molecule 1 (VCAM-1) & -43 & $-441,83$ & 0.625 \\
\hline
\end{tabular}

Table 6. Dysregulated genes of the GO class "extracellular matrix" (Metacore).

\begin{tabular}{|c|c|c|}
\hline Symbol & Gene name & $\begin{array}{l}\log _{2} \text { fold-change } \\
\text { MC1 vs. control }\end{array}$ \\
\hline COL22A1 & collagen type XXII alpha 1 chain & 1.545 \\
\hline COL4A5 & collagen type IV alpha 5 chain & 1.15 \\
\hline WNT2 & Wingless-type MMTV integration site family, member 2 & 1.037 \\
\hline HAI2 & Kunitz-type protease inhibitor 2 & 0.832 \\
\hline KAL1 & Anosmin 1 & 0.826 \\
\hline BMP3В & Bone morphogenetic protein 3B & 0.822 \\
\hline LRRC15 & Leucine rich repeat containing 15 & 0.794 \\
\hline SERPINA3 & serpin family A member 3 & 0.792 \\
\hline ADAMTS16 & A disintegrin and metalloproteinase with thrombospondin motifs 16 & 0.751 \\
\hline COL18A1 & collagen type IIXX alpha 1 chain & 0.746 \\
\hline PLAT & Tissue plasminogen activator & 0.746 \\
\hline COL1A1 & collagen type I alpha 1 chain & 0.676 \\
\hline FBLN2 & Fibulin 2 & 0.656 \\
\hline FBLN5 & Fibulin 5 & 0.649 \\
\hline GREM1 & Gremlin 1 & 0.644 \\
\hline PCOLCE2 & Pro-collagen C-endopeptidase enhancer 2 & 0.633 \\
\hline LAMB3 & Laminin subunit beta-3 & 0.628 \\
\hline SERPINE2 & Serpin peptidase inhibitor, clade E, member 2 & 0.612 \\
\hline COL4A2 & collagen type IV alpha 2 chain & 0.602 \\
\hline TNC & Tenascin C & -0.638 \\
\hline FGFR2 & Fibroblast growth factor recpetor 2 & -0.666 \\
\hline LUM & Lumican & -0.69 \\
\hline CCBE1 & Collagen and calcium-binding EGF domain-containing protein 1 & -0.717 \\
\hline TIG2 & Tazarotene-induced gene 2 protein & -0.747 \\
\hline COL11A2 & collagen type XI alpha 2 chain & -0.748 \\
\hline HPSE & Heparanase 1 & -0.841 \\
\hline CHI3L1 & Chitinase-3-like protein 1 & -0.867 \\
\hline CPXM2 & Carboxypeptidase X, M14 family member 2 & -1.188 \\
\hline
\end{tabular}


TGF- $\beta 1$ (Peprotech)]. Myofibroblast differentiation was determined based on the expression of profibrotic genes (COL1A1, ACTA2), gel contractility and $\alpha$-SMA protein expression as described above. Effects of TGF- $\beta 1$ stimulation was compared between MC1 and control using paired $t$-test.

Assay 12: FACS of LEPR high MC1 and control BMSCs MC1 and control BMSCs were stained for LEPR as described in assay 2. The $20 \%$ highest expressing LEPR MC1 BMSCs (LEPR ${ }^{\text {high }}$ ) were sorted using a BD FACSAria ${ }^{\mathrm{TM}}$ Fusion. The same sorting gate of MC1 was applied to the intra-patient control. Statistical analysis of TGF- $\beta 1$ effect and adipogenic differentiation was performed as described in assay 3 and 11.

\section{Statistical analysis}

All statistical analyses were performed using GraphPad Prism version 8.4.0. An outcome was considered significant if $p<0.05$ ( $p<0.01$ for RNA sequencing). Normal distribution was tested using the Shapiro Wilk test. Parametric tests were run in case of normal distribution and non-parametric tests in case of non-normal distribution.

\section{Results}

\section{Patient characteristics}

Of the 14 included patients, 3 (21.4\%) were male and had an average age of $67.6 \pm 11.6$ years. Patients were in average overweight (BMI: $31.4 \pm 6.3 \mathrm{~kg} / \mathrm{m}^{2}$ ), had a median VASback of 8.0, IQR $=6.0,9.0$ and a median VASleg of $6.5, \mathrm{IQR}=4.5,8.0$. ODI score was high $(49.3 \% \pm 15.7 \%)$. Bone marrow aspirates were most often taken from vertebral level L4 (control: $n=5$; MC1: $n=4)$ and L5 (control: $n=4 ; \mathrm{MC} 1: n=6)$. Degree of disc degeneration ( $p=0.098$; control: $5, \mathrm{IQR}=3,5$; $\mathrm{MC1}: 5, \mathrm{IQR}=5,5)$ and total endplate score $(p=0.011$; control: 3, IQR = 1, 4; MC1: 5, IQR = 5, 6) was higher at levels of MC1 than controls.

\section{Stemness of MC1 BMSCs, expression of BMSC subpopulation markers and CFU-F}

MSCs are defined by their expression of the consensus surface markers and their ability to differentiate into adipocytes, osteoblasts and chondrocytes. BMSCs from control and MC1 both expressed high levels of the consensus marker sequence without significant differences $(p=0.527$; MC1: $93.2 \% \pm 4.6 \%$; control: $93.8 \% \pm 3.7 \%)$. A decreased adipogenic differentiation potential of MC1 BMSCs compared to intra-patient control BMSCs $(-17.5 \% \pm 14.7 \%, p=0.007)$ was observed. There was no significant difference in osteoblast $(+15.2 \% \pm 65.4 \%, p=0.505)$ and chondrocyte differentiation capacity $(-0.9 \% \pm 24.0 \%, p=0.915)$ (Fig. 2a).

Flow cytometric analysis of markers describing BMSC subpopulations revealed no significant changes in expression of all tested surface markers (LEPR, CXCL12, CD54, CD140a, CD146, CD271, NG2, CD106, nestin) (Table 5). Despite the high variability, in all tested patients, CXCL12 was higher expressed in MC1 than control $(p=0.063)$ and LEPR was higher expressed in 4 out of 5 MC1 cells $(p=0.180)$ (Fig. $2 \mathbf{b}$ ). Expression of LEPR and CXLC12 correlated $(r=0.95$, $p=0.014)$. Furthermore, expression of CD271, NG2 and CD106 correlated $(r=0.91-0.99, p=0.001-0.031)$ as well as nestin and CD146 $(r=0.99, p=0.002)$.

To quantify the relative frequency of BMSCs in MC1 bone marrow, CFU-F of nucleated cells was quantified in MC1 and control bone marrow aspirates. MC1 contained more CFU-F than control bone marrow (+68.2\% $\pm 57.9 \%, p=0.035)$ (Fig. $2 \mathrm{c}$ ).

\section{RNA sequencing and expression of pro-fibrotic genes and proteins}

Bulk RNA sequencing comparing MC1 to control BMSCs identified 219 DEGs. GO analysis of the DEGs with DAVID $\left(p=2.2 \times 10^{-6}\right)$ and Metacore $\left(p=7.2 \times 10^{-13}\right)$ revealed an enrichment of the ECM (Table 6). In the GO class "cellular components", the top items were all related to ECM or collagen and were all up-regulated (Fig. 3a). "Extracellular matrix structural constituent" $\left(p=2.3 \times 10^{-6}\right)$ and "extracellular matrix organisation" $\left(p=3.5 \times 10^{-4}\right)$ were also the top enriched GOs in the classes "molecular function" and "biological process", respectively. GSEA identified the Notch pathway, Wnt/ $\beta$-catenin pathway, Hedgehog pathway and EMT as top enriched gene sets. Furthermore, a specific fibrosis gene set was highly enriched (Fig. 3b). GSEA of the canonical pathways gene sets derived from the Reactome pathway database (820 gene sets) and enrichment map visualisation in Cytoscape identified "extracellular matrix organisation" as a central process connected with several functions related to ECM formation and modification (Fig. 3c).

Analysis of pro-fibrotic gene expression by qPCR revealed a slight upregulation of ACTA2 $\left(\log _{2}\right.$ fold-change $\left.=0.31 \pm 0.40, p=0.050\right)$ and of COL1A1 $\left(\log _{2}\right.$ fold-change $\left.=0.45 \pm 0.57, p=0.046\right)$ as well as a marked up-regulation of MMP9 $\left(\log _{2}\right.$ fold-change $=2.11 \pm 1.46, p=0.0009$ ) in MC1 (Fig. $3 \mathbf{d})$. The increased ACTA2 expression in MC1 could not be confirmed on the protein level as measured by Western blot $(p=0.922,-2.24 \%$, IQR $=-25.09 \%$, $+22.4 \%)$ or flow cytometry $(p=0.467,+17.1 \pm 47.6 \%)$ (Fig. 3e). Concentration of pro-collagen type I alpha 1 was significantly higher in starvation medium from MC1 BMSCs compared to control BMSCs $(p=0.031$, $+11.2 \%$, IQR $=+7.60 \%, 22.07 \%$ ) (Fig. 3f).

\section{Gel contraction, matrix adhesion and expression of FAK/p-FAK}

Contraction capacities of BMSCs were quantified by their ability to contract collagen gels. MC1 BMSCs contracted collagen gels more than control BMSCs, resulting in smaller gels after $24 \mathrm{~h}(-9.6 \% \pm 6.62 \%$, $p=0.017$ ) (Fig. 4a). 
a

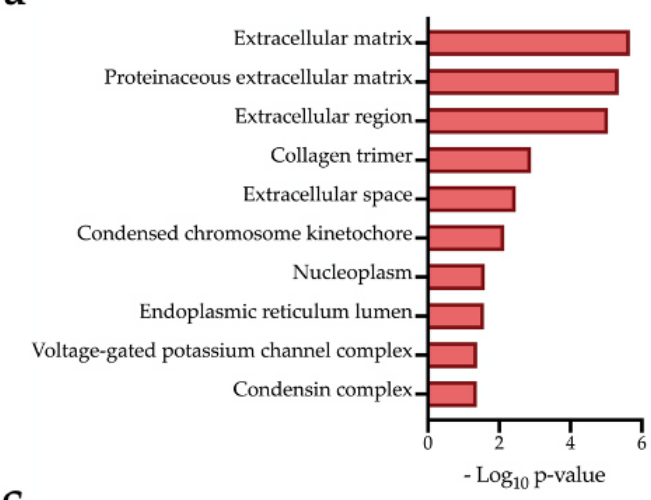

C

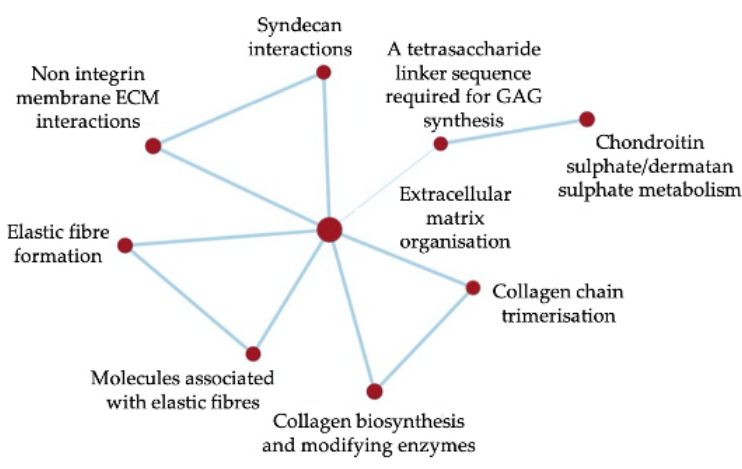

d

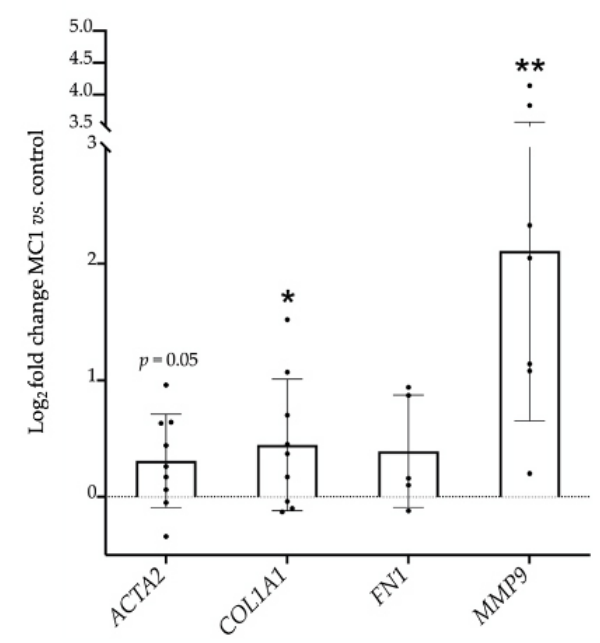

b
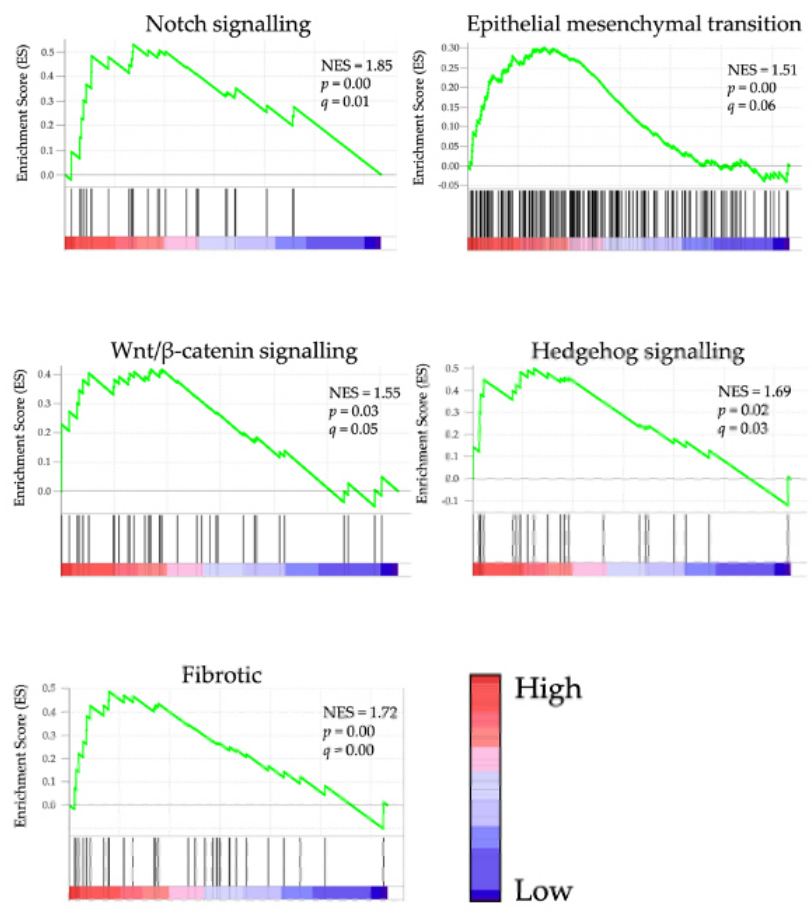

f

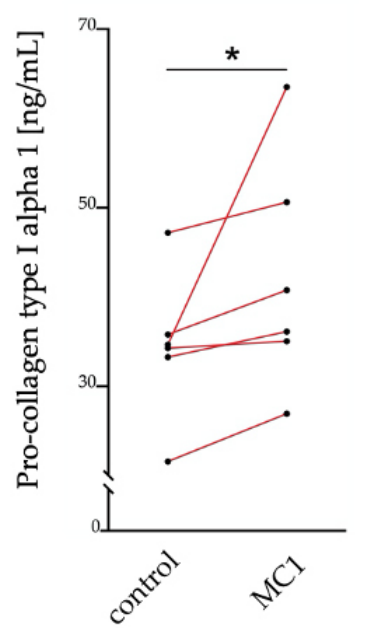

Fig. 3. Transcriptome profile of MC1 versus intra-patient control BMSCs. (a-c) Bulk RNA sequencing of in vitro-expanded $\mathrm{MC} 1$ and intra-patient control BMSCs $(n=4+4)$ was performed (Illumina). Genes were considered as DEG for $p<0.01$ and $\log _{2}$ fold change $> \pm 0.5$. GO enrichment was performed in DAVID, GSEA with GSEA software. (a) The 10 most significantly overrepresented cellular components comparing MC1 to control. (b) GSEA of "hallmark" gene sets revealed enriched pro-fibrotic biological processes. (c) Enrichment map visualisation of pathways (Reactome database) enriched in MC1 BMSCs with gene sets $p<0.01$, FDR $q$-value $<0.1$ and an overlap coefficient of 0.5 . Node size displays number of genes within a gene set, thickness of connection line represents extent of overlap between gene sets. (d) Expression of profibrotic genes was up-regulated in MC1 BMSCs. Pro-fibrotic gene expression was compared between MC1 and control by RT-qPCR. Samples were measured in technical duplicates $(n=5+5-9+9)$ and $\triangle \triangle \mathrm{Cq}(\mathrm{MC1}$ to control) values were tested against the null hypothesis $(\mu 0=0)$ with one sample $t$-test. $\log _{2}$ fold change of $\Delta \Delta \mathrm{Cq}$ are represented. (e) Representative Western blot of $\alpha$-SMA expression. $\alpha$-SMA protein level was detected by Western blot $(n=10+10)$ and band signal intensities were quantified 3 times using Image J. $\alpha$-SMA band signal intensities were normalised to $\beta$-actin and percentages of MC1 and control intensities were compared with paired Wilcoxon test. (f) Synthesis of pro-collagen type I alpha 1 was increased in MC1 BMSCs. BMSCs were cultured for $48 \mathrm{~h}$ in starvation medium with $1 \%$ FCS. After medium change, medium was conditioned for $24 \mathrm{~h}$ and pro-collagen type I alpha 1 was measured by ELISA. MC1 and control were measured in biological duplicates and ELISA was performed in technical duplicates. ${ }^{*} p<0.05 ;{ }^{* *} p<0.01$. 
Adhesion to matrix of MC1 and control BMSCs was compared by counting the cells that attached to fibronectin-coated, collagen I-coated or uncoated dishes. More cells bound to fibronectin-coated dishes $(+7.9 \% \pm 11.6 \%, p=0.047)$ and to uncoated dishes $(+9.4 \% \pm 12.9, p=0.036)$. The increase in binding to type I collagen-coated dishes was not significant (+ $6.6 \% \pm 10.1, p=0.110)$ (Fig. 4b).

Whether the increased matrix adhesion was due to increased expression of integrins was analysed. There was no difference in the gene expression of all tested integrins except for ITGB1 ( $\log _{2}$ fold-change $=0.32 \pm 0.26, p=0.022$ ) (Table 7). However, flow cytometric analysis $(p=0.871)$ and Western blot of ITGB1 ( $p=0.938,+5.31 \%$, IQR $=-25.9 \%,+12.7 \%)$ showed no significant difference in ITGB1 protein level (data not shown). a

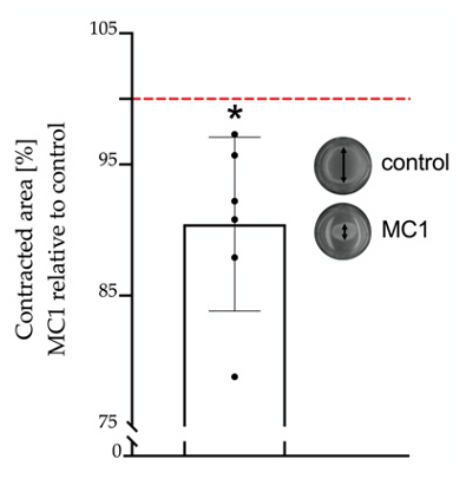

C

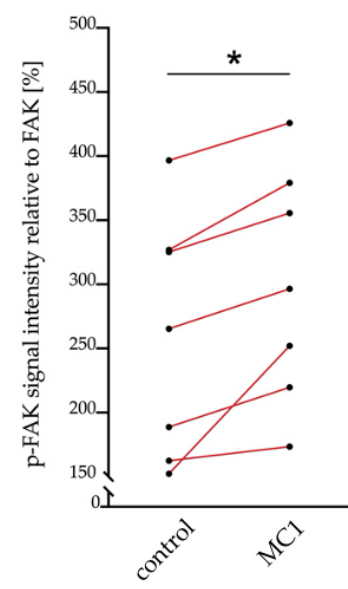

Phosphorylation of FAK is central in downstream signalling of integrins and is important in mediating cell contractility (Vallée and Lecarpentier, 2019). Therefore, the fraction of phosphorylated FAK to total FAK was measured and calculated by Western blot. The percentage of phosphorylated FAK from total FAK (p-FAK/FAK) was significantly higher in MC1 BMSCs (+ 30.9 \%, IQR = + $29.8 \%, 40.7 \%, p=0.016)$ while total FAK normalised to $\beta$-actin (FAK/ $\beta$-actin) was not increased $(+2.8 \%$, IQR $=-1.1 \%, 8.7 \%$, $p=0.468)($ Fig. 4c,d).

\section{Responsiveness to TGF- $\beta 1$ of bulk BMSCs}

The pro-fibrotic gene expression of $\mathrm{MC} 1$ and control BMSCs in response to $24 \mathrm{~h}$ TGF- $\beta 1$ stimulation was compared. qPCR analysis revealed high interpatient variability and no increase in ACTA2 d

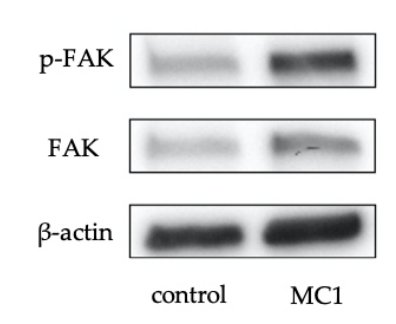

b

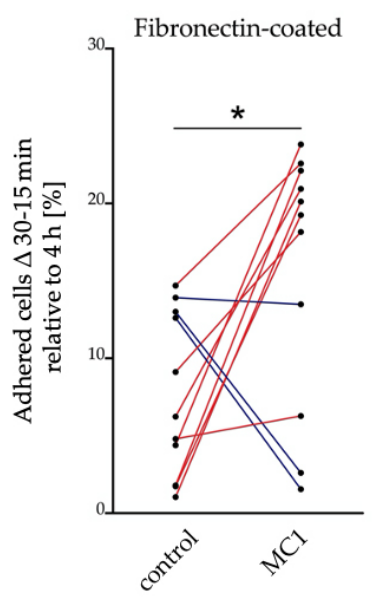

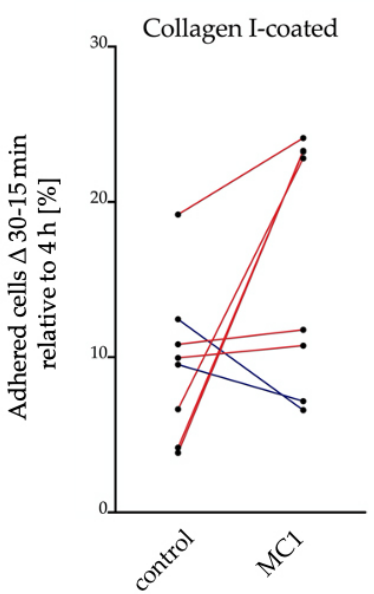
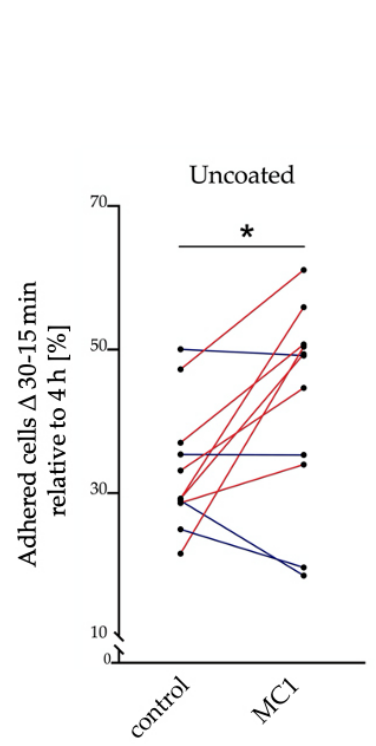

Fig. 4. Collagen gel contractility and cell matrix adhesion. (a) MC1 BMSCs contracted gels more than the respective control BMSCs. MC1 and control collagen gel contractility was measured in biological duplicates. BMSCs were mixed with rat tail collagen I and incubated for $24 \mathrm{~h}$. Gel surface area was measured using Image J. Size of MC1 BMSC gels was normalised to control BMSC gels (100\%) of the same patient and tested against null hypothesis ( $\mu 0=100 \%$ ) using one sample $t$-test. (b) Cell-matrix adhesion: increased adhesion of MC1 BMSCs to fibronectin and uncoated plates. BMSC adhesion to fibronectin-coated, collagen I-coated and uncoated $(n=8+8-11+11)$ plates were assessed between 15 and 30 min after cell seeding by counting adhered cells. Cell numbers were normalised to the respective $4 \mathrm{~h}$ counts. Percentage increase of adherent MC1 and control BMSCs were compared by paired t-tests. MC1 and control adhesion was measured in sextuplicate. (c) p-FAK was increased in MC1 BMSCs. FAK and p-FAK protein level were detected by Western blot $(n=7+7)$ and band signal intensities were quantified 3 times using Image J. p-FAK band signal intensities were normalised to total FAK (\% total FAK) and percentages of MC1 and control intensities were compared with paired Wilcoxon test. (d) Representative Western blot of p-FAK, FAK and $\beta$-actin. ${ }^{*} p<0.05$. 
Table 7. Gene expression analysis of integrin subunits. Mean and SD of $\log _{2}$ fold change $\left(\log _{2} \mathrm{fc}\right)$ are indicated. ${ }^{*} p<0.05$.

\begin{tabular}{|c|c|c|c|}
\hline Gene & Mean $\log _{2} \mathbf{f c}$ & SD $\log _{2} \mathbf{f c}$ & $p$-value \\
\hline ITGA1 & 0.120 & 0.605 & 0.586 \\
\hline ITGA2 & 0.100 & 0.520 & 0.609 \\
\hline ITGA3 & -0.340 & 1.179 & 0.447 \\
\hline ITGA4 & 0.000 & 0.768 & 0.989 \\
\hline ITGA5 & 0.130 & 0.616 & 0.561 \\
\hline ITGA6 & -0.350 & 0.897 & 0.306 \\
\hline ITGA7 & 0.080 & 1.087 & 0.832 \\
\hline ITGA8 & 0.908 & 2.047 & 0.450 \\
\hline ITGA10 & 0.347 & 0.769 & 0.243 \\
\hline ITGA11 & 0.170 & 0.704 & 0.514 \\
\hline ITGAV & 0.225 & 0.466 & 0.215 \\
\hline ITGB1 & 0.290 & 0.306 & $0.022^{*}$ \\
\hline ITGB2 & -0.010 & 1.404 & 0.984 \\
\hline ITGB3 & -0.041 & 0.395 & 0.779 \\
\hline ITGB5 & -0.018 & 0.419 & 0.906 \\
\hline ITGB8 & -0.150 & 0.939 & 0.661 \\
\hline
\end{tabular}

expression after stimulation in $\mathrm{MC} 1 \log _{2}$ foldchange $=0.11 \pm 1.61)$ and control $\left(\log _{2}\right.$ fold-change $=-0.25 \pm 1.58)$ and no difference between MC1 and control $(p=0.648)$. Similarly, COL1A1 ( $\log _{2}$ fold-change $\mathrm{MC1}=0.09 \pm 0.15, \log _{2}$ fold-change control $=-0.01 \pm 0.32, p=0.656)$, COL4A5 $\left(\mathrm{Log}_{2}\right.$ fold-change $\mathrm{MC1}=0.31 \pm 0.93, \mathrm{Log}_{2}$ fold-change control $=-0.11 \pm 3.97, p=0.920)$, FN1 $\left(\log _{2}\right.$ foldchange $\mathrm{MC1}=0.32 \pm 0.92, \log _{2}$ fold-change control $=0.25 \pm 0.51, p=0.900)$ and MMP9 (Log foldchange $\mathrm{MC1}=3.77 \pm 8.98, \log _{2}$ fold-change control $=-0.31 \pm 2.04, p=0.302)$ expression remained unchanged (Fig. 5a). $\alpha$-SMA expression measured by Western blot upon TGF- $\beta 1$ stimulation was not significantly increased in MC1 $(-0.3 \% \pm 75.71 \%)$ and control (-9.54\% $\pm 48.01 \%)$ and did also not differ between MC1 and control BMSCs $(p=0.606)$ (Fig. $5 b)$. Additionally, there was no difference in collagen gel contraction in response to TGF- $\beta 1$ in MC1 $(-2.39 \% \pm 15.62 \%)$ and control $(+12.57 \% \pm 14.52 \%)$ and there was also no difference between MC1 and control BMSCs $(p=0.210)$.

\section{Analysis of LEPR ${ }^{\text {high }}$ BMSCs}

To test if LEPR ${ }^{\text {high }}$ BMSC s could undergo myofibroblast differentiation, $\alpha$-SMA was quantified by Western blot after TGF- $\beta 1$ stimulation of sorted LEPR ${ }^{\text {high }}$ BMSCs of MC1 and control. Whereas $\alpha-S M A$ expression upon TGF- $\beta 1$ stimulation in LEPR ${ }^{\text {high }}$ control BMSCs was not changed $(-8.7 \% \pm 33.55 \%$, $p=0.693)$, TGF- $\beta 1$ stimulation led to a strong increase in $\alpha$-SMA expression in LEPR ${ }^{\text {high }}$ MC1 BMSCs $(+69.23 \% \pm 37.9 \%, p=0.035)$ (Fig. 5c). Furthermore, the adipogenic differentiation capacity of LEPR high sorted BMSCs was compared. LEPR ${ }^{\text {high }}$ MC1 BMSCs of the 3 analysed patients had a trend towards an increased adipogenic differentiation capacity $(+32.17 \% \pm 23.29 \%, p=0.140)$ (Fig. 5d).

\section{Discussion}

Bone marrow fibrosis is a pathophysiological important mechanism in MC1 and may have diagnostic and clinical relevance (Dudli et al., 2017; Dudli et al., 2020; Modic et al., 1988). The present study showed that BMSCs in MC1 have a profibrotic phenotype compared to BMSCs from control vertebral bone marrow from the same patient. This phenotype is characterised by excessive production of ECM, increased cell contraction capability and enhanced adhesion. Increased FAK phosphorylation was identified as an important fibrotic characteristic of MC1 BMSCs, suggesting a mechanistical link between increased cell adhesion and cell contractility. An overrepresented LEPR high subpopulation in MC1 but not control could undergo myofibroblast differentiation and, hence, be a possible driver of fibrosis in MC1.

Increased CFU-F and LEPR expression and reduced adipogenic differentiation capacity in MC1

BMSCs are a heterogeneous population of fibroblastic cells. Sub-populations of BMSCs are responsible for bone marrow fibrosis in other conditions (Decker et al., 2017; Schneider et al., 2017). Whether the BMSC population in MC1 was different from the control BMSC population of the adjacent vertebra was investigated. CD14-, CD19-, CD34-, CD45-, CD73+, $\mathrm{CD}^{+}{ }^{+}$and $\mathrm{CD} 105^{+}$marker expression was compared. Even though these markers are indistinguishably expressed on fibroblasts and MSCs, this surface marker expression combination is an important criterion that defines MSCs (Denu et al., 2016; Dominici et al., 2006). MC1 and control BMSCs did not differ in the expression of the MSC consensus markers CD14-, $\mathrm{CD}^{-}{ }^{-}, \mathrm{CD} 34^{-}, \mathrm{CD}_{4}^{-}, \mathrm{CD}^{+} 3^{+}, \mathrm{CD}^{\circ}{ }^{+}$and $\mathrm{CD} 105^{+}$but MC1 BMSCs tended to express more CXCL12 and LEPR with correlating expression of CXCL12 and LEPR. Despite the high patient variability in absolute expression levels, these findings were consistent and may indicate that a CXCL12 ${ }^{+} \mathrm{LEPR}^{+}$population was overrepresented in MC1. CXCL12 ${ }^{+} \mathrm{LEPR}^{+}$cells are a perisinusoidal population that create a niche for haematopoietic stem cells and give rise to osteoblasts (Acar et al., 2015; Galán-Díez and Kousteni, 2018). Neovascularisation in MC1 may go along with expansion of a CXCL12 ${ }^{+} \mathrm{LEPR}^{+}$population on the newly formed sinusoidal surface (Bailey et al., 2011). Increased number of CFU-F in MC1 could support this notion as almost all CFU-F are $\mathrm{LEPR}^{+}$BMSCs (Decker et al., 2017; Zhou et al., 2014). Expansion of $\mathrm{CXCL12}^{+} \mathrm{LEPR}^{+}$cells could be a response to endplate and trabecular bone damage in $\mathrm{MC} 1$ because $\mathrm{LEPR}^{+}$ 
BMSCs proliferate after bone injury and give rise to osteoblasts (Galán-Díez and Kousteni, 2018; Zhou et al., 2014). Importantly, CXCL12 ${ }^{+} \mathrm{LEPR}^{+}$cells have been identified as a major source of myofibroblasts in bone marrow fibrosis in primary myelofibrosis (Decker et al., 2017). Although primary myelofibrosis is a distinct pathological entity, the study by Decker et al. (2017) showed that CXCL12 ${ }^{+} \mathrm{LEPR}^{+}$cells are capable of undergoing myofibroblast differentiation and contribute to bone marrow fibrosis.

LEPR-expressing BMSCs are the main progenitor cells that generate adipocytes, osteoblasts and chondrocytes in the bone marrow (Zhou et al., 2014). Differentiation of BMSCs in MC1 may be affected by the inflammatory environment (Huang et al., 2014), bony endplate damages (Zhou et al., 2014) and proosteoclastic/anti-osteoblastic factors draining from the adjacent intervertebral discs through endplate damages into the bone marrow (Dudli et al., 2017;

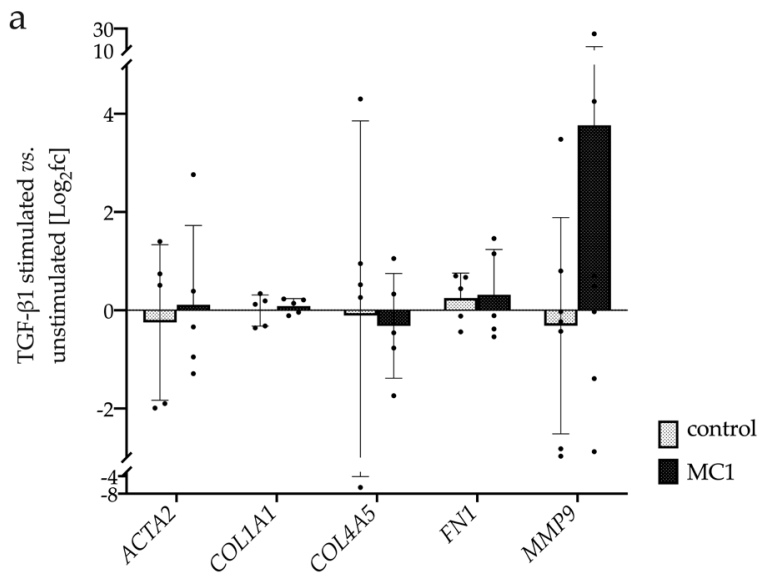

C

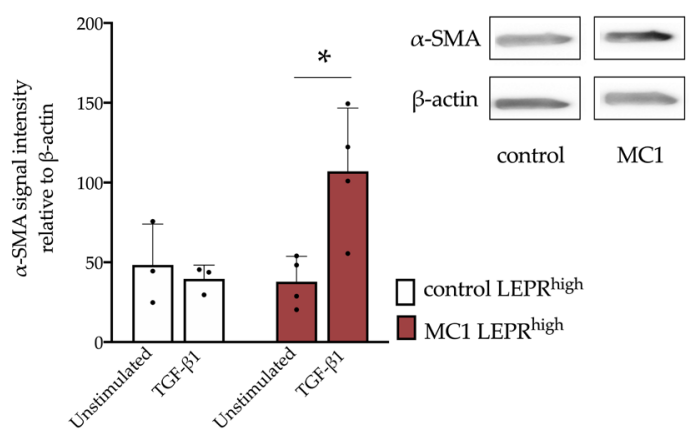

Rajasekaran et al., 2004; Torkki et al., 2016). In this complex environment, a reduced adipogenic differentiation capacity but no significant difference in osteogenic and chondrogenic differentiation were found. This indicated a net loss of the trilineage differentiation capacity and stemness and suggested an unspecific fibroblastic polarisation of MC1 BMSCs. A loss of adipogenic differentiation capacity of fibroblasts has also been shown in a bleomycin-induced mouse model of fibrosis (El Agha et al., 2017b). Lung fibroblasts underwent a shift away from adipogenic towards myofibroblasts polarisation, while resolution of fibrosis reversed the shift. However, the present study results indicated that LEPR ${ }^{\text {high }}$ BMSCs did not contribute to the reduced adipogenic differentiation capacity. In contrast, LEPR $^{\text {high }}$ BMSCs in MC1 tended to differentiate more into adipocytes than LEPR ${ }^{\text {high }}$ BMSC s of controls. This corresponded with the finding of Yue et al. (2016)

b

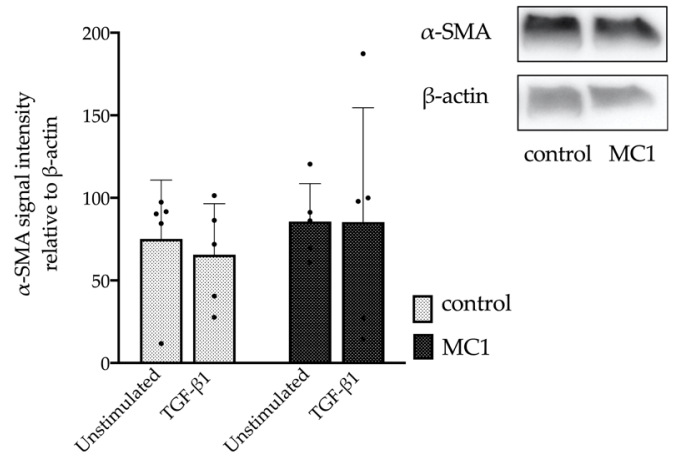

d

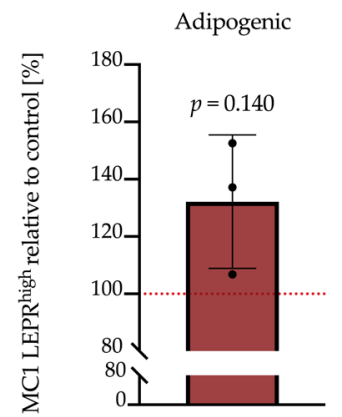

Fig. 5. MC1 and control BMSCs in response to TGF- $\beta 1$. (a) TGF- $\beta 1$ stimulation did not result in a different pro-fibrotic gene expression between MC1 and control BMSCs. Gene expression of $24 \mathrm{~h}$ stimulation with $10 \mathrm{ng} / \mathrm{mL}$ TGF- $\beta 1$ was measured by RT-qPCR $(n=5+5)$ in technical duplicates. Effects of TGF- $\beta 1$ stimulation was compared between MC1 and control by paired $t$-test. (b) No difference in $\alpha$-SMA protein level upon TGF- $\beta 1$ stimulation in MC1 and control BMSCs. $\alpha$-SMA protein level of TGF- $\beta 1$-stimulated and -unstimulated MC1 and control BMSCs was detected by Western blot $(n=5+5)$. Band signal intensities were quantified 3 times using Image J. Effects of TGF- $\beta 1$ stimulation were compared by paired $t$-test. (c) TGF- $\beta 1$ stimulation of LEPR ${ }^{\text {high }}$-sorted MC1 BMSCs resulted in a significant increase in $\alpha$-SMA production, whereas there was no change in LEPR ${ }^{\text {high }}$-sorted control BMSCs. $\alpha$-SMA protein level in TGF- $\beta 1$-stimulated and

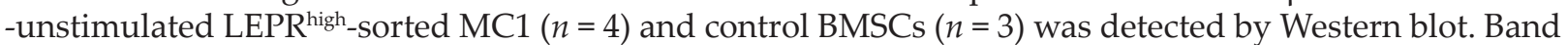
signal intensities were quantified 3 times using Image J. Effects of TGF- $\beta 1$ stimulation were compared by paired $t$-test. (d) LEPR ${ }^{\text {high }}$ MC1 BMSCs had a trend towards increased adipogenic differentiation capacity. Adipogenic differentiation capacity of LEPR ${ }^{\text {high }}$-sorted MC1 and intra-patient control was measured in sextuplicate $(n=3+3)$. LEPR $^{\text {high }}$ MC1 was normalised to intra-patient LEPR ${ }^{\text {high }}$ control $(100 \%)$ and tested against null hypothesis $\left(\mu 0=100 \%\right.$ ) using one sample $t$-test. $\log _{2}$ fc: $\log _{2}$ fold-change. ${ }^{*}<<0.05$. 
who showed that leptin receptor on mesenchymal stromal cells promotes adipogenesis. The present study findings suggested that the reduced adipogenic differentiation capacity of "bulk" MC1 BMSCs was caused by the LEPR ${ }^{\text {low }}$ BMSC population and that a myofibroblastic BMSC phenotype was rather linked to increased adipogenesis than reduced adipogenesis. The underlying mechanisms for the altered adipogenic differentiation capacities in LEPR $^{\text {high }}$ and LEPR ${ }^{\text {low }}$ remain unknown.

Together, these findings suggested that a perivascular population was overrepresented in MC1 and that MC1 BMSC differentiation capacity was reduced. The reduced adipogenic differentiation capacity could most likely not be attributed to the overrepresented LEPR ${ }^{\text {high }}$ population in MC1 BMSCs. It needs to be shown if the over represented population and the reduced adipogenic differentiation potential of MC1 BMSCs were causally linked to fibrosis in MC1.

\section{Pro-fibrotic ECM production and signalling in MC1 BMSCs}

The transcriptome of MC1 BMSCs showed a profibrotic phenotype of MC1 BMSCs, with increased ECM deposition and activation of pro-fibrotic signalling pathways. ECM constituents and modifying enzymes were enriched in GO analysis and were the most enriched gene sets in the pathway analysis. Increased synthesis of ECM is a hallmark of fibrosis and is causally linked to clinical manifestations in many fibrotic pathologies as it restricts proper tissue function (Wynn, 2008). Synthesis of pro-collagen type I alpha 1, the prototypical ECM constituent secreted by myofibroblasts, was increased in MC1 BMSCs and type XXII collagen alpha 1 and type IV collagen alpha 5 were the top dysregulated ECM constituents of the MC1 BMSC transcriptome. Type XXII collagen has been identified as a marker of the transition of skin fibroblasts to myofibroblasts in systemic sclerosis (Watanabe et al., 2019). Type IV collagen is a prototypic ECM protein of myofibroblasts and pro-collagen type IV turnover has been identified as a prognostic marker for the disease progression of systemic sclerosis [Dobrota et al. (2020). Circulating collagen turnover markers are specifically changed in very early systemic sclerosis. Ann Rheum Dis 79: 159; conference abstract; Klingberg et al., 2013]. Importantly, circulating pro-collagen type IV has been reported to be increased in peripheral blood of MC1 patients (Dudli et al., 2020). This shows that increased ECM secretion through fibrotic mechanisms in MC1 has a potential diagnostic value. Findings suggested a link between increased serum values of type IV collagen and the fibrotic pathomechanism in MC1 bone marrow. If this can be validated, it is an important finding as it provides face validity for circulating pro-collagen- 4 as $\mathrm{MC} 1$ biomarker and underscores the clinical significance of bone marrow fibrosis in MC1.
Besides increased ECM secretion, fibrosis and EMT were identified, as well as the three signalling pathways, Notch, Wnt/ $\beta$-catenin and Hedgehog as the top enriched gene sets in MC1. This corroborated the pro-fibrotic phenotype of MC1 BMSCs as all three signalling pathways mediated fibrotic processes across different organs and tissues, including lung, kidney, skin, liver and heart (Burgy and Königshoff, 2018; Hu et al., 2015; Hu and Phan, 2016; Lam and Gottardi, 2011). Inhibition of Notch, Wnt/ $\beta$-catenin and Hedgehog signalling inhibits tissue fibrosis through mechanisms that inhibit EMT (Fontaine et al., 2008; Wang et al., 2019; Yuan et al., 2016). Notch signalling also promotes PMT, which could explain the increase in the pericyte-like CXCL12 ${ }^{+} \mathrm{LEPR}^{+}$ population. Furthermore, Notch, Wnt/ $\beta$-catenin and Hedgehog signalling affect MSC differentiation. Notch signalling generally inhibits any lineage differentiation but enhances MSC proliferation (Dong et al., 2010). Hedgehog and Wnt/ $\beta$-catenin signalling promote osteoblast differentiation and inhibit adipocyte differentiation (Fontaine et al., 2008; Yuan et al., 2016). Therefore, increased Notch, Wnt/ $\beta$-catenin and Hedgehog signalling may relate to increased CFU-F and decreased adipogenic differentiation capacity as found in the present study.

\section{Increased cell adhesion, cell contractility and FAK phosphorylation}

Phosphorylation of FAK has been identified as an important mechanism in fibroblasts causing bone marrow fibrosis and lung fibrosis (Desterke et al., 2015; Lagares et al., 2012; Zhao et al., 2016). Increased matrix adhesion, gel contractility and FAK phosphorylation were found in MC1 BMSCs. This was a strong indication for a pro-fibrotic phenotype of MC1 BMSCs and that FAK was important in MC1 fibrosis.

FAK is a key kinase of the ECM-cytoskeleton mechanotransduction via integrins and mediates several fibrotic mechanisms. FAK modulates adhesion strength through integrin activation and modulates cell contractility by $\alpha$-SMA and actin polymerisation at focal adhesions (Michael et al., 2009). Phosphorylation of FAK occurs after integrin binding to matrix and is associated with the cytoplasmic domain of integrin $\beta$ subunits. Integrins are $\alpha \beta$-heterodimers and, of the $\beta$-subunits, integrin $\beta 1$ conveys a key role as it binds almost all $\alpha$-subunits to form matrix receptors. The $\alpha$-subunit defines the specificity of the integrin receptor to bind fibronectin, collagen or laminin. In fibrosis, integrin $\beta 1$ plays a central role and its inhibition or knock-down reduces fibrosis (Basta et al., 2020; Liu et al., 2009; Zhao et al., 2016). MC1 BMSCs adhered stronger to fibronectin and uncoated plastic dishes, indicating an increased non-specific matrix binding. Next, it was assessed whether increased non-specific binding was caused by overexpression of specific integrins and in particular of the universal subunit integrin 
$\beta 1$. No change in gene transcription of 16 tested integrin subunits was found, except for integrin $\beta 1$, which was marginally but significantly upregulated. However, increased integrin $\beta 1$ expression could not be validated at protein level by Western blot and flow cytometric analysis. Matrix adhesion is also modulated by FAK through 'inside-out' signalling that activates integrins through conformational changes (Michael et al., 2009). Therefore, increased matrix adhesion in MC1 BMSCs was not due to overexpression of integrins but might be due to FAK phosphorylation through other pathways.

Phosphorylation of FAK is important for the formation of $\alpha$-SMA stress fibres that mediate cell contractility. MC1 BMSCs had an increased cell contractility without a relevant increase in $\alpha$-SMA expression. This suggested a mechanism independent of $\alpha$-SMA expression. Organisation and polymerisation of actin is FAK-mediated and an important early step in the formation of focal adhesion that transduce mechanical forces. It might be that MC1 BMSCs had a more efficient way to form nascent adhesions and increase cell contractility without increasing $\alpha$-SMA expression.

\section{Responsiveness to myofibroblast differentiation}

Myofibroblasts are $\alpha$-SMA-expressing highly contractile cells that produce large amounts of ECM. TGF- $\beta 1$ is a master regulator of fibrosis and promotes myofibroblast differentiation (Van Caam et al., 2018). No difference in pro-fibrotic gene expression, $\alpha$-SMA production and collagen gel contraction were found between MC1 and control BMSCs in response to TGF- $\beta 1$. As Decker et al. (2017) identified LEPR-expressing BMSCs as the cellular origin of the collagen-producing myofibroblasts in bone marrow fibrosis, it was investigated whether TGF- $\beta 1$ induced myofibroblast differentiation of LEPR ${ }^{\text {high }}$ BMSCs.

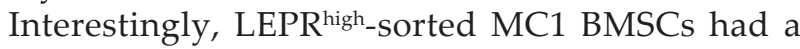
significantly upregulated $\alpha$-SMA production upon TGF- $\beta 1$ stimulation, whereas LEPR ${ }^{\text {high }}$-sorted control BMSCs had not. These results showed two things. First, that a LEPR ${ }^{\text {high }}$ subpopulation of MC1 BMSCs could undergo myofibroblast differentiation, which corresponds to the bone marrow fibrosis contributing CXCL12 ${ }^{+} \mathrm{LEPR}^{+}$phenotype discovered by Decker et al. (2017). Second, since LEPR ${ }^{\text {high }}$ control BMSCs did not undergo TGF- $\beta 1$-induced myofibroblast differentiation, LEPR expression on BMSCs was not a sufficient criterion for myofibroblast differentiation. Therefore, MC1 LEPR ${ }^{\text {high }}$ BMSCs but not control LEPR $^{\text {high }}$ BMSCs were susceptible to differentiate into myofibroblasts. It remains unknown what makes MC1 LEPR ${ }^{\text {high }}$ BMSCs susceptible to myofibroblast differentiation, yet chronic inflammation as well as biomechanical changes within $\mathrm{MC1}$ bone marrow might be critical factors.

In summary, while collectively BMSCs in MC1 had a pro-fibrotic phenotype, only a LEPR ${ }^{\text {high }}$ BMSC population in MC1 could undergo myofibroblast differentiation. The role of the different BMSC subpopulations in the fibrotic pathomechanism of MC1 awaits investigations. It also needs to be demonstrated if $\mathrm{MC1}$ bone marrow indeed contains $\alpha$-SMA positive myofibroblasts.

\section{Limitations and critical evaluation}

BMSCs from patients with lumbar MC1 who underwent lumbar spinal fusion were investigated. Since LBP is a multifactorial disease and MC1 is not an indication for surgery, patients had different surgical indications. Most suffered from spinal stenosis, listhesis, scoliosis, sagittal misalignment or facet joint degeneration at the surgical level. Hence, different aetiologies may have caused MC1. However, mechanical overload and endplate damage always occur in MC1 and seem to be independent of the primary diagnosis (Dudli et al., 2016). Therefore, pathophysiological bone marrow changes in MC1 may be less diverse than their aetiology. Nevertheless, to select patients with mainly axial and not radicular pain, only patients with higher VAS scores for back pain than leg pain were enrolled. Also, patients with prior spinal fusion, malignancies and infectious disease were excluded to eliminate potential confounders.

Size and type of MC1 (pure MC1 vs. mixed MC1/ MC2) may also affect BMSC phenotype. Only BMSCs from $\mathrm{MC}$ lesions that were classified as $\mathrm{MC1}$ or mixed $\mathrm{MC1/MC2}$ were investigated. Pure MC1 are rare, in particular in patients undergoing spinal fusion, as this is the treatment of last resort and MC1 at the time of operation may have evolved over time through different phases of MC1 and MC2 before.

The quality of the aspirate may affect the investigated BMSC population. Intraoperative $X$-ray confirmed that the bone marrow aspiration needle was placed at the correct site before taking the aspirate. However, it was not possible to monitor the marrow space which was aspirated. Therefore, it was not possible to validate post-operatively if $\mathrm{MC1}$ aspirate contained cells only from MC1 lesions or if cells from non-affected areas were aspirated as well. Control bone marrow is heterogeneous as well and often shows small areas of signal intensity changes related to focal changes in marrow composition. Therefore, aspirates from control marrow may have also contained some potential pathological cells. The aspiration volume was limited to maximal $3.5 \mathrm{~mL}$. This volume limits the risk of aspirating peripheral blood and bone marrow cells outside the target area (Brooimans et al., 2009) and at the same time guarantees a large enough cell pool to obtain a representative population from the target area.

Culturing BMSCs changes their expression profile (Ghazanfari et al., 2017). However, a thorough characterisation of primary BMSCs is not possible because primary BMSCs are a rare population in bone marrow and not enough cells would have been available for all assays. MC1 are a chronic condition and many changes are likely stably imprinted and do not change during expansion. Therefore, cells 
from MC1 and control were expanded in vitro and always used at the same passage (passage 3,4 or 5) to minimise any culture expansion effects.

It was not possible to correlate changes across different assays as not all were performed with cells from the same patient. This limits a more powerful interpretation of the data as patient-to-patient variation was considerable for most assays. However, MC1 BMSCs were always compared to intra-patient control BMSCs for each assay, which eliminated most of patient-related confounders and allowed for a paired analysis.

\section{Conclusion}

In summary, the present is the first study characterising BMSCs in MC1. Important profibrotic changes in MC1 BMSC and a LEPR ${ }^{\text {high }}$ MC1 BMSC subpopulation susceptible to myofibroblast differentiation were found. Fibrosis is a hallmark of MC1 and BMSCs in MC1 represent a potential therapeutic target to control fibrosis in MC1. A causal link between the pro-fibrotic phenotype and clinical characteristics needs to be demonstrated.

\section{Acknowledgements}

We would like to thank the group of Prof. Jess Snedeker for the technical support. This work was supported by the Balgrist Foundation, the VELUX Foundation (project number 1170) and the Baugarten Foundation. Research was supported by the National Institute of Arthritis and Musculoskeletal and Skin Diseases of the National Institutes of Health under Award Number U19AR076737 and the Clinical Research Priority Program of the University of Zurich (CRPP Pain). The content is solely the responsibility of the authors and does not necessarily represent the official views of the National Institutes of Health.

\section{References}

Acar M, Kocherlakota KS, Murphy MM, Peyer JG, Oguro H, Inra CN, Jaiyeola C, Zhao Z, LubyPhelps K, Morrison SJ (2015) Deep imaging of bone marrow shows non-dividing stem cells are mainly perisinusoidal. Nature 526: 126-130.

Azizidoost S, Shanaki Bavarsad M, Shanaki Bavarsad M, Shahrabi S, Jaseb K, Rahim F, Shahjahani M, Saba F, Ghorbani M, Saki N (2015) The role of notch signaling in bone marrow niche. Hematology 20: 93-103.

Bailey JF, Liebenberg E, Degmetich S, Lotz JC (2011) Innervation patterns of PGP 9.5-positive nerve fibers within the human lumbar vertebra. J Anat 218: 263-270.

Barilani M, Banfi F, Sironi S, Ragni E, Guillaumin S, Polveraccio F, Rosso L, Moro M, Astori G,
Pozzobon M, Lazzari L (2018) Low-affinity nerve growth factor receptor (CD271) heterogeneous expression in adult and fetal mesenchymal stromal cells. Sci Rep 8: 9321. DOI: 10.1038/s41598-018-275878.

Basta J, Robbins L, Stout L, Prinsen MJ, Griggs DW, Rauchman M (2020) Pharmacologic inhibition of RGD-binding integrins ameliorates fibrosis and improves function following kidney injury. Physiol Rep 8: e14329. DOI: 10.14814/phy2.14329.

Brooimans RA, Kraan J, van Putten W, Cornelissen JJ, Löwenberg B, Gratama JW (2009) Flow cytometric differential of leukocyte populations in normal bone marrow: influence of peripheral blood contamination. Cytometry B Clin Cytom 76: 18-26.

Burgy O, Königshoff M (2018) The WNT signaling pathways in wound healing and fibrosis. Matrix Biol 68-69: 67-80.

Chung CB, Vande Berg BC, Tavernier T, Cotten A, Laredo JD, Vallee C, Malghem J (2004) End plate marrow changes in the asymptomatic lumbosacral spine: frequency, distribution and correlation with age and degenerative changes. Skeletal Radiol 33: 399-404.

Decker M, Martinez-Morentin L, Wang G, Lee Y, Liu Q, Leslie J, Ding L (2017) Leptinreceptor-expressing bone marrow stromal cells are myofibroblasts in primary myelofibrosis. Nat Cell Biol 19: 677-688.

Denu RA, Nemcek S, Bloom DD, Goodrich AD, Kim J, Mosher DF, Hematti P (2016) fibroblasts and mesenchymal stromal/stem cells are phenotypically indistinguishable. Acta Haematol 136: 85-97.

Desterke C, Martinaud C, Ruzehaji N, Le BousseKerdilès MC (2015) Inflammation as a keystone of bone marrow stroma alterations in primary myelofibrosis. Mediators Inflamm 2015: 415024. DOI: 10.1155/2015/415024.

Dominici M, Le Blanc K, Mueller I, SlaperCortenbach I, Marini FC, Krause DS, Deans RJ, Keating A, Prockop DJ, Horwitz EM (2006) Minimal criteria for defining multipotent mesenchymal stromal cells. the international society for cellular therapy position statement. Cytotherapy 8: 315-317.

Dong Y, Jesse AM, Kohn A, Gunnell LM, Honjo T, Zuscik MJ, O'Keefe RJ, Hilton MJ (2010) RBPjkappadependent notch signaling regulates mesenchymal progenitor cell proliferation and differentiation during skeletal development. Development 137: 1461-1471.

Dudli S, Ballatori A, Bay-Jensen AC, McCormick ZL, O'Neill CW, Demir-Deviren S, Krug R, Heggli I, Juengel A, Karppinen J, Brunner F, Farshad M, Distler O, Lotz JC, Fields AJ (2020) Serum biomarkers for connective tissue and basement membrane remodeling are associated with vertebral endplate bone marrow lesions as seen on MRI (Modic changes). Int J Mol Sci 21: 1-14.

Dudli S, Fields AJ, Samartzis D, Karppinen J, Lotz JC (2016) Pathobiology of Modic changes. Eur Spine J 25: 3723-3734. 
Dudli S, Sing DC, Hu SS, Berven SH, Burch S, Deviren V, Cheng I, Tay BKB, Alamin TF, Ith MAM, Pietras EM, Lotz JC (2017) ISSLS prize in basic science 2017: Intervertebral disc/bone marrow cross-talk with Modic changes. Eur Spine J 26: 1362-1373.

El Agha E, Kramann R, Schneider RK, Li X, Seeger W, Humphreys BD, Bellusci S (2017a) Mesenchymal stem cells in fibrotic disease. Cell Stem Cell 21: 166177.

El Agha E, Moiseenko A, Kheirollahi V, De Langhe S, Crnkovic S, Kwapiszewska G, Kosanovic D, Schwind F, Schermuly RT, Henneke I, MacKenzie BA, Quantius J, Herold S, Ntokou A, Ahlbrecht K, Morty RE, Günther A, Seeger W, Bellusci S (2017b) Twoway conversion between lipogenic and myogenic fibroblastic phenotypes marks the progression and resolution of lung fibrosis. Cell Stem Cell 20: 261-273.

Enobakhare BO, Bader DL, Lee DA (1996) Quantification of sulfated glycosaminoglycans in chondrocyte/alginate cultures, by use of 1,9-dimethylmethylene blue. Anal Biochem 243: 189-191.

Fields AJ, Liebenberg EC, Lotz JC (2014) Innervation of pathologies in the lumbar vertebral end plate and intervertebral disc. Spine J 14: 513-521.

Fontaine C, Cousin W, Plaisant M, Dani C, Peraldi P (2008) Hedgehog signaling alters adipocyte maturation of human mesenchymal stem cells. Stem Cells 26: 1037-1046.

Galán-Díez M, Kousteni S (2018) A bone marrow niche-derived molecular switch between osteogenesis and hematopoiesis. Genes Dev 32: 324-326.

Ghazanfari R, Zacharaki Di, Li H, Ching Lim H, Soneji S, Scheding S (2017) human primary bone marrow mesenchymal stromal cells and their in vitro progenies display distinct transcriptional profile signatures. Sci Rep 7: 1-10.

Hoch AI, Leach JK (2015) Concise review: optimizing expansion of bone marrow mesenchymal stem/stromal cells for clinical applications. Stem Cells Transl Med 4: 412. DOI: 10.5966/sctm.20130196erratum.

Hu B, Phan SH (2016) Notch in fibrosis and as a target of anti-fibrotic therapy. Pharmacol Res 108: 57-64.

Hu L, Lin X, Lu H, Chen B, Bai Y (2015) An overview of hedgehog signaling in fibrosis. Mol Pharmacol 87: 174-182.

Huang RL, Yuan Y, Zou GM, Liu G, Tu J, Li Q (2014) LPS-stimulated inflammatory environment inhibits BMP-2-induced osteoblastic differentiation through crosstalk between TLR4/MyD88/NF- $\mathrm{B}$ and BMP/Smad signaling. Stem Cells Dev 23: 277-289.

Jacobsen K, Kravitz J, Kincade P, Osmond D (1996) Adhesion receptors on bone marrow stromal cells: in vivo expression of vascular cell adhesion molecule-1 by reticular cells and sinusoidal endothelium in normal and gamma-irradiated mice. Blood 87: 73-82.

Järvinen J, Karppinen J, Niinimäki J, Haapea M, Grönblad M, Luoma K, Rinne E (2015) Association between changes in lumbar Modic changes and low back symptoms over a two-year period clinical diagnostics and imaging. BMC Musculoskelet Disord 16: 98. DOI: 10.1186/s12891-015-0540-3.

Jensen OK, Nielsen CV, Sørensen JS, StengaardPedersen K (2014) Type 1 Modic changes was a significant risk factor for 1-year outcome in sick-listed low back pain patients: a nested cohort study using magnetic resonance imaging of the lumbar spine. Spine J 14: 2568-2581.

Jensen TS, Karppinen J, Sorensen JS, Niinimäki J, Leboeuf-Yde C (2008) Vertebral endplate signal changes (Modic change): a systematic literature review of prevalence and association with nonspecific low back pain. Eur Spine J 17: 1407-1422.

Kääpä E, Luoma K, Pitkäniemi J, Kerttula L, Grönblad M (2012) Correlation of size and type of modic types 1 and 2 lesions with clinical symptoms: a descriptive study in a subgroup of patients with chronic low back pain on the basis of a university hospital patient sample. Spine (Phila Pa 1976) 37:1349.

Klingberg F, Hinz B, White ES (2013) The myofibroblast matrix: implications for tissue repair and fibrosis. J Pathol 229: 298-309.

Kondo Y, Irie K, Ikegame M, Ejiri S, Hanada K, Ozawa H (2001) Role of stromal cells in osteoclast differentiation in bone marrow. J Bone Miner Metab 19: 352-358.

Lagares D, Busnadiego O, García-Fernández RA, Kapoor M, Liu S, Carter DE, Abraham D, Shi-Wen X, Carreira P, Fontaine BA, Shea BS, Tager AM, Leask A, Lamas S, Rodríguez-Pascual F (2012) Inhibition of focal adhesion kinase prevents experimental lung fibrosis and myofibroblast formation. Arthritis Rheum 64: 1653-1664.

Lam AP, Gottardi CJ (2011) $\beta$-catenin signaling: a novel mediator of fibrosis and potential therapeutic target. Curr Opin Rheumatol 23: 562-567.

Liu S, Kapoor M, Denton CP, Abraham DJ, Leask A (2009) Loss of beta1 integrin in mouse fibroblasts results in resistance to skin scleroderma in a mouse model. Arthritis Rheum 60: 2817-2821.

Lotz JC, Fields AJ, Liebenberg EC (2013) The Role of the vertebral end plate in low back pain. Glob Spine J 3: 153-164.

Michael KE, Dumbauld DW, Burns KL, Hanks SK, García AJ (2009) Focal adhesion kinase modulates cell adhesion strengthening via integrin activation. Mol Biol Cell 20: 2508-2519.

Modic MT, Steinberg PM, Ross JS, Masaryk TJ, Carter JR (1988) Degenerative disk disease: assessment of changes in vertebral body marrow with MR imaging. Radiology 166: 193-199.

Nguyen C, Poiraudeau S, Rannou F (2015) From Modic 1 vertebral-endplate subchondral bone signal changes detected by MRI to the concept of "active discopathy." Ann Rheum Dis 74: 1488-1494.

Ohtori S, Inoue G, Ito T, Koshi T, Ozawa T, Doya H, Saito T, Moriya H, Takahashi K (2006) 
Tumor necrosis factor-immunoreactive cells and PGP 9.5-immunoreactive nerve fibers in vertebral endplates of patients with discogenic low back pain and modic type 1 or type 2 changes on MRI. Spine (Phila Pa 1976) 31: 1026-1031.

Perilli E, Parkinson IH, Truong LH, Chong KC, Fazzalari NL, Osti OL (2015) Modic (endplate) changes in the lumbar spine: bone micro-architecture and remodelling. Eur Spine J 24: 1926-1934.

Rajasekaran S, Babu JN, Arun R, Armstrong BRW, Shetty AP, Murugan S (2004) ISSLS prize winner: a study of diffusion in human lumbar discs: a serial magnetic resonance imaging study documenting the influence of the endplate on diffusion in normal and degenerate discs. Spine (Phila Pa 1976) 29: 2654-2667.

Rajasekaran S, Venkatadass K, Naresh Babu J, Ganesh K, Shetty AP (2008) Pharmacological enhancement of disc diffusion and differentiation of healthy, ageing, and degenerated discs: results from in vivo serial post-contrast MRI studies in 365 human lumbar discs. Eur Spine J 17: 626-643.

Schistad EI, Espeland A, Rygh LJ, Røe C, Gjerstad J (2014) The association between Modic changes and pain during 1-year follow-up in patients with lumbar radicular pain. Skeletal Radiol 43: 1271-1279.

Schneider RK, Mullally A, Dugourd A, Peisker F, Hoogenboezem R, Van Strien PMH, Bindels EM, Heckl D, Büsche G, Fleck D, Müller-Newen G, Wongboonsin J, Ventura Ferreira M, Puelles VG, Saez-Rodriguez J, Ebert BL, Humphreys BD, Kramann R (2017) Gli1+ mesenchymal stromal cells are a key driver of bone marrow fibrosis and an important cellular therapeutic target. Cell Stem Cell 20: 785-800.

Sørile A, Moholdt V, Kvistad KA, Nygaard OP, Ingebrigtsen T, Iversen T, Kloster R, Solberg TK (2012) Modic type I changes and recovery of back pain after lumbar microdiscectomy. Eur Spine J 21: 2252-2258.

Subramanian A, Tamayo P, Mootha VK, Mukherjee S, Ebert BL, Gillette MA, Paulovich A, Pomeroy SL, Golub TR, Lander ES, Mesirov JP (2005) Gene set enrichment analysis: a knowledge-based approach for interpreting genome-wide expression profiles. Proc Natl Acad Sci U S A 102: 15545-15550.

Torkki M, Majuri ML, Wolff H, Koskelainen T, Haapea M, Niinimäki J, Alenius H, Lotz J, Karppinen J (2016) Osteoclast activators are elevated in intervertebral disks with Modic changes among patients operated for herniated nucleus pulposus. Eur Spine J 25: 207-216.

Tormin A, Li O, Brune JC, Walsh S, Schütz B, Ehinger M, Ditzel N, Kassem M, Scheding S (2011) CD146 expression on primary nonhematopoietic bone marrow stem cells is correlated with in situ localisation. Blood 117: 5067-5077.

Vallée A, Lecarpentier Y (2019) TGF- $\beta$ in fibrosis by acting as a conductor for contractile properties of myofibroblasts. Cell Biosci 9: 98. DOI: 10.1186/s13578019-0362-3.

Van Caam A, Vonk M, Van Den Hoogen F, Van Lent P, Van Der Kraan P (2018) Unraveling SSc pathophysiology; the myofibroblast. Front Immunol 9: 1-22.

Wang Y-C, Chen Q, Luo J-M, Nie J, Meng Q-H, Shuai W, Xie H, Xia J-M, Wang H (2019) Notch1 promotes the pericyte-myofibroblast transition in idiopathic pulmonary fibrosis through the PDGFR/ ROCK1 signal pathway. Exp Mol Med 51: 1-11.

Watanabe T, Frost DAB, Mlakar L, Heywood J, Da Silveira WA, Hardiman G, Feghali-Bostwick C (2019) A human skin model recapitulates systemic sclerosis dermal fibrosis and identifies COL22A1 as a TGF $\beta$ early response gene that mediates fibroblast to myofibroblast transition. Genes (Basel) 10: 75. DOI: 10.3390/genes10020075.

Weishaupt D, Zanetti M, Hodler J, Min K, Fuchs B, Pfirrmann CWA, Boos N (2001) Painful lumbar disk derangement: relevance of end plate abnormalities at MR imaging. Radiology 218: 420-427.

Wohlfahrt T, Rauber S, Uebe S, Luber M, Soare A, Ekici A, Weber S, Matei AE, Chen CW, Maier C, Karouzakis E, Kiener HP, Pachera E, Dees C, Beyer C, Daniel C, Gelse K, Kremer AE, Naschberger E, Stürzl M, Butter F, Sticherling M, Finotto S, Kreuter A, Kaplan MH, Jüngel A, Gay S, Nutt SL, Boykin DW, Poon GMK, Distler O, Schett G, Distler JHW, Ramming A (2019) PU.1 controls fibroblast polarisation and tissue fibrosis. Nature 566: 344-349.

Wynn TA (2008) Cellular and molecular mechanisms of fibrosis. J Pathol 214: 199-210.

Yuan Z, Li Q, Luo S, Liu Z, Luo D, Zhang B, Zhang D, Rao P, Xiao J (2016) PPAR $\gamma$ and Wnt signaling in adipogenic and osteogenic differentiation of mesenchymal stem cells. Curr Stem Cell Res Ther 11: 216-225.

Yue R, Zhou BO, Shimada IS, Zhao Z, Morrison SJ (2016) Leptin receptor promotes adipogenesis and reduces osteogenesis by regulating mesenchymal stromal cells in adult bone marrow. Cell Stem Cell 18: 782-796.

Zhao XK, Cheng Y, Liang Cheng M, Yu L, Mu M, Li H, Liu Y, Zhang B, Yao Y, Guo H, Wang R, Zhang $Q$ (2016) Focal adhesion kinase regulates fibroblast migration via integrin beta-1 and plays a central role in fibrosis. Sci Rep 6: 19276. DOI: 10.1038/srep19276.

Zhou BO, Yue R, Murphy MM, Peyer JG, Morrison SJ (2014) Leptin-receptor-expressing mesenchymal stromal cells represent the main source of bone formed by adult bone marrow. Cell Stem Cell 15: 154-168.

Ziegler P, Boettcher S, Takizawa H, Manz MG, Brümmendorf TH (2016) LPS-stimulated human bone marrow stroma cells support myeloid cell development and progenitor cell maintenance. Ann Hematol 95: 173-178.

\section{Web Reference}

1. https://www.ebi.ac.uk/ena/browser/view/ PRJEB39993 [26.05.2021] 


\section{Discussion with Reviewers}

Reviewer: Cells from an adjacent level have been used as a matched control group. Is there a possibility that BMSCs from the control group might have been affected by a crosstalk with MC1 cells?

Authors: The reviewer points out an important point. The bone marrow is not an isolated organ and stands in physical and biological exchange with surrounding tissues. Nevertheless, MC are separated from healthy bone marrow with a clear demarcation line, as already pointed out by Michael Modic's original study (Modic et al., 1988). Therefore, diseased tissue and healthy tissue can clearly be distinguished. While paracrine communication may occur and affect BMSC phenotype, the local environment of control and MC1 bone marrow are decisive. This results in MC1 and control BMSC phenotypes that show relevant differences, as shown in the present study.

Elena Della Bella: MSCs are frequently suggested and used in clinical trials for the treatment of lowback pain and disc-related disorders. If confirmed that BMSCs contribute substantially to MC1 changes, do the authors think that this might be a contraindication for possible therapeutic use of MSCs in patients with MC1 lesions?

Authors: This is a great question. The past and ongoing clinical trials using MSCs to regenerate degenerated discs did not stratify for patients with MC. In contrast, some of them explicitly excluded them, possibly to reduce patient heterogeneity. Therefore, no data is available that shows the effect of $\mathrm{MC}$ on disc regeneration studies.

We personally do not think that $\mathrm{MC}$ in the adjacent bone marrow are a contraindication. In contrast, the immunomodulatory effect of MSCs could be critical to break the pro-inflammatory and pro-fibrotic crosstalk of discs and bone marrow at levels with MC (Dudli et al., 2017). However, a contraindication is more likely the advanced stage of disc degeneration that typically is present at levels with MC. Disc regeneration studies generally aim at regenerating a moderately degenerated disc. Late stage degenerated discs might not be ideal for regeneration studies.

Editor's note: The Scientific Editor responsible for this paper was Sibylle Grad. 